\title{
Speciation control during Suzuki-Miyaura cross-coupling of haloaryl and haloalkenyl MIDA boronic esters
}

\author{
James W. B. Fyfe,${ }^{[a]}$ Elena Valverde,${ }^{[b]}$ Ciaran P. Seath,${ }^{[a]}$ Alan R. Kennedy, ${ }^{[a]}$ Joanna M. Redmond, ${ }^{[c]}$ \\ Niall A. Anderson, ${ }^{[c]}$ and Allan J. B. Watson*[a]
}

\begin{abstract}
Boronic acid solution speciation can be controlled during the Suzuki-Miyaura cross-coupling of haloaryl MIDA boronic esters to enable the formal homologation of boronic acid derivatives. The reaction is contingent upon control of the basic biphase and is thermodynamically driven: temperature control provides highly chemoselective access to either BMIDA adducts at room temperature or BPin products at elevated temperature. Control experiments and solubility analyses have provided some insight into the mechanistic operation of the formal homologation process.
\end{abstract}

\section{Introduction}

The development of protected boronic acids has been pivotal to the growth of iterative Suzuki-Miyaura cross-coupling processes. $^{[1,2]}$ In particular, the boronic esters ( $N$-coordinated boronates) derived from $\mathrm{N}$-methyliminodiacetic acid $(\mathrm{BMIDA})^{[2 \mathrm{a}, \mathrm{b}, \mathrm{d}, 3-5]}$ and the aminoboranes derived from 1,8diaminonaphthalene $(\mathrm{BDAN})^{[2 \mathrm{c}, \mathrm{d}, 6,7]}$ are readily installed and removable protecting groups that render iterative SuzukiMiyaura cross-coupling relatively facile: following a first crosscoupling event, protecting group hydrolysis under basic (BMIDA) or acidic (BDAN) conditions liberates the reactive parent boronic acid, primed for further cross-coupling (Figure 1a).

Similar to the majority of methods for the preparation of reactive boron species, these chemistries proceed via stoichiometric and step-wise manipulation of a single reactive boron species, ${ }^{[8]}$ such as a boronic acid. Conversion of a protected boronic acid to an alternative reactive boron species, such as a boronic acid pinacol ester (BPin) typically proceeds via the same synthetic pathway; conversion of BMIDA to BPin requires hydrolysis and subsequent esterification (Figure 1b). ${ }^{[4 a, d]}$ We recently demonstrated that it is possible to convert a BMIDA ester to a BPin ester during the Suzuki-Miyaura crosscoupling of a haloaryl BMIDA with an aryl BPin. ${ }^{[9]}$ This is achieved via pinacol recycling via control of multiboron solution speciation leading to a formal $\mathrm{sp}^{2}$ BPin homologation (Figure 1c).

[a] J. W. B. Fyfe, C. P. Seath, Dr A. R. Kennedy, Dr A. J. B. Watson WestCHEM, Department of Pure and Applied Chemistry University of Strathclyde 295 Cathedral Street, Glasgow G1 1XL, UK.

E-mail: allan.watson.100@strath.ac.uk

[b] E. Valverde

Laboratori de Química Farmacèutica

Facultat de Farmàcia and Institute of Biomedicine (IBUB) Universitat de Barcelona

Av. Joan XXIII, Barcelona, E-08028, Spain.

[c] Dr J. M. Redmond, Dr N. A. Anderson GlaxoSmithKline

Medicines Research Centre

Gunnels Wood Road, Stevenage, Hertfordshire, SG1 2NY, UK

Supporting information for this article is given via a link at the end of the document. a) Iterative cross-coupling using protected boronic acids (Burke, Suginome) $\mathrm{Ar}^{1}-\mathrm{B}(\mathrm{OH})_{2}$

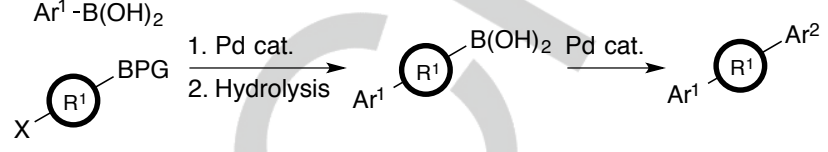

b) Conversion of BMIDA to BPin after cross-coupling (Burke)

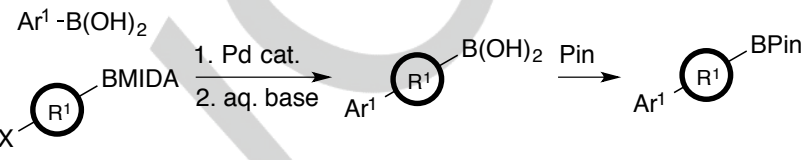

c) Formal BPin homologation via controlled speciation

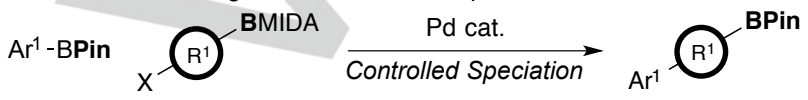

BMIDA:

Figure 1. (a) Iterative cross-coupling using protected boronic acids, (b) crosscoupling of BMIDA followed by conversion to BPin; (c) formal BPin homologation by controlled speciation. DAN, 1,8-diaminonaphthalene; MIDA, $\mathrm{N}$-methyliminodiacetic acid; Pin, pinacol/pinacolato.

Here we provide the full details of this study demonstrating (i) the dependence of the reaction on $\mathrm{pH}$ as well as the physical properties of the base, (ii) that the chemoselectivity of boron speciation can be thermodynamically controlled to provide selective access to either BMIDA or BPin products, and (iii) that the general concept of speciation control is transferrable across boronic acids, BPin esters, and catechol esters. We also provide an analysis of the parameters resulting in effective speciation control for this transformation and insight into the issues surrounding anomalous reactions.

\section{Results and Discussion}

Boronic acids and esters are known to exhibit complex and dynamic solution speciation equilibria. ${ }^{[10]}$ Chemoselective control of boronic acid solution speciation comprising a mixture of boron species may therefore be expected to be difficult based on the requirement to simultaneously manipulate interlinked equilibria. Accordingly, the preparation of synthetically useful boron species, such as boronic acids and esters, is typically performed by manipulation of single boron component to avoid possible difficulties arising from these equilibria, potentially leading to mixtures of products. ${ }^{[10,11]}$ However, exerting control over the equilibria associated with multiboron systems may provide useful and more efficient methods for the preparation of valuable boron reagents without resorting to the possibly more laborious 
single molecule manipulations that are common throughout this preparative area.

We sought to explore this idea in the context of SuzukiMiyaura cross-coupling using two different boronic esters, specifically BPin esters (1) and haloaryl BMIDA esters (2) with the goal of ascertaining whether the boron speciation may be controlled during the reaction to produce a new BPin ester and thereby establishing a formal homologation process that would offer increased step efficiency over conventional approaches. ${ }^{[9]}$

The overall reaction was envisaged to take place via four elementary steps (Scheme 1): (i) C-C bond formation resulting from conventional Suzuki-Miyaura cross-coupling to generate an intermediate product BMIDA 3; (ii) hydrolysis of $\mathbf{3}$ to the parent boronic acid 5; (iii) hydrolysis of the Suzuki-Miyaura byproduct HO-BPin 4 to liberate pinacol; and (iv) esterification of $\mathbf{5}$ with the in situ generated pinacol to deliver the desired, formally homologated, product 6 .

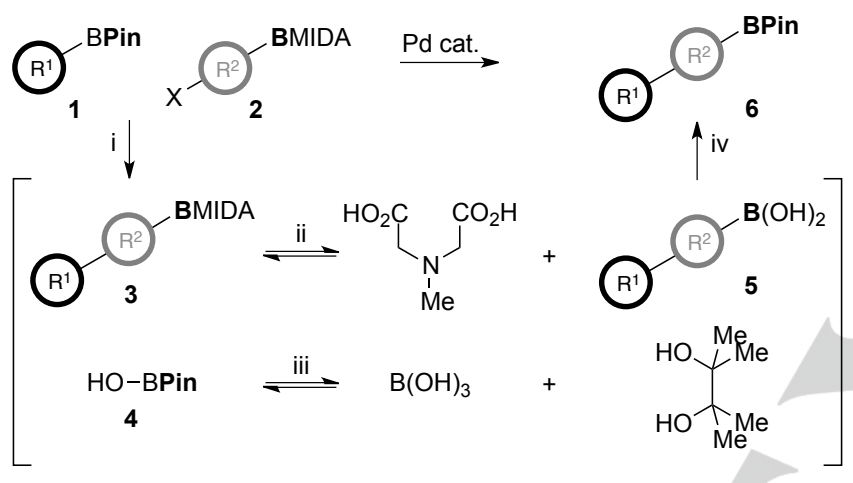

Scheme 1. Proposed formal homologation of aryl BPin via controlled boron speciation during Suzuki-Miyaura cross-coupling of haloaryl BMIDA esters.

Each of the elementary steps are theoretically straightforward and are supported by studies from other research groups: cross-coupling of aryl BPin 1 with haloaryl BMIDA 2 to deliver the BMIDA 3 is typically a high yielding process. ${ }^{[4]]}$ The subsequent hydrolysis of 3 to the latent boronic acid 5 is readily achieved with either $\mathrm{NaOH}$ or $\mathrm{K}_{3} \mathrm{PO}_{4}{ }^{[4 \mathrm{e}, 5 \mathrm{~d}, \mathrm{~g}, \mathrm{q}]}$ Hydrolysis of boric acid esters, such as 4 , is similarly facile under aqueous basic conditions. ${ }^{[12]}$ The final esterification of 5 with pinacol is also typically a high yielding and rapid process under a variety of conditions ranging from acidic to basic. ${ }^{[12,13]}$ Based on this, steps (ii)-(iv) could all tentatively be controlled using an appropriate aqueous basic medium.

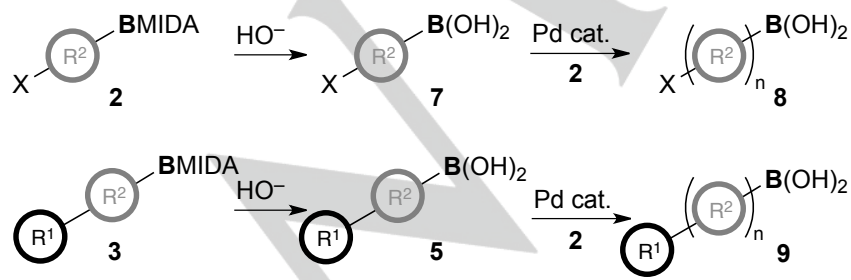

Scheme 2. Oligomerization of haloaryl BMIDA species during Suzuki-Miyaura cross-coupling due to premature in situ hydrolysis.
However, aqueous base is incompatible with the first reaction event due to the base lability of BMIDA esters. ${ }^{[4,5 d, g, q, q]}$ Cross-coupling of BMIDA-containing compounds is typically performed under anhydrous conditions to avoid hydrolysis. In the envisioned process in Scheme 1, premature hydrolysis of 2 or $\mathbf{3}$ would lead to $\mathbf{5}$ and/or $\mathbf{7}$, which may undergo uncontrolled oligomerization to 8 and/or 9 (Scheme 2).

In addition, the reaction would need to be staged appropriately to avoid cross-coupling conflict due to the similarities in reactivity profiles of starting material $\mathbf{1}$, intermediate boronic acid 5, and product 6 towards crosscoupling.

Design Plan. To reconcile the requirement for anhydrous conditions during cross-coupling and the aqueous basic conditions that would facilitate control over the subsequent reaction events, we sought to establish an internal water reservoir. This would be achieved by exploiting the physical properties of the inorganic bases typically associated with Suzuki-Miyaura cross-coupling. ${ }^{[14]}$ Many of these bases are hygroscopic, and generate stable hydrates. In contrast to the majority of Suzuki-Miyaura reactions, which employ relatively large quantities of $\mathrm{H}_{2} \mathrm{O}$ (commonly 4:1-7:1), ${ }^{[1 \mathrm{e}]}$ addition of a controlled quantity of $\mathrm{H}_{2} \mathrm{O}$ to a suitably hygroscopic inorganic base was proposed to sequester $\mathrm{H}_{2} \mathrm{O}$ and safeguard BMIDA integrity during cross-coupling while simultaneously providing sufficient $\mathrm{H}_{2} \mathrm{O}$ and base within the reaction mixture to facilitate the downstream hydrolytic and esterification events.

Accordingly, we began by interrogating a benchmark SuzukiMiyaura cross-coupling reaction between phenylboronic acid pinacol ester (BPin) 10 and 4-bromophenyl BMIDA 11a using a common $\mathrm{Pd}$ catalyst $\left(\mathrm{PdCl}_{2} \mathrm{dppf}\right)$ in THF using two typical inorganic bases, $\mathrm{K}_{3} \mathrm{PO}_{4}$ and $\mathrm{Cs}_{2} \mathrm{CO}_{3}$, in conjunction with a comparatively restricted quantity of $\mathrm{H}_{2} \mathrm{O}(10: 1)$ vs. typical Suzuki-Miyaura reactions (Table 1).

Table 1. Initial reactions with $\mathrm{K}_{3} \mathrm{PO}_{4}$ and $\mathrm{Cs}_{2} \mathrm{CO}_{3}$ using 10:1 THF: $\mathrm{H}_{2} \mathrm{O}$.

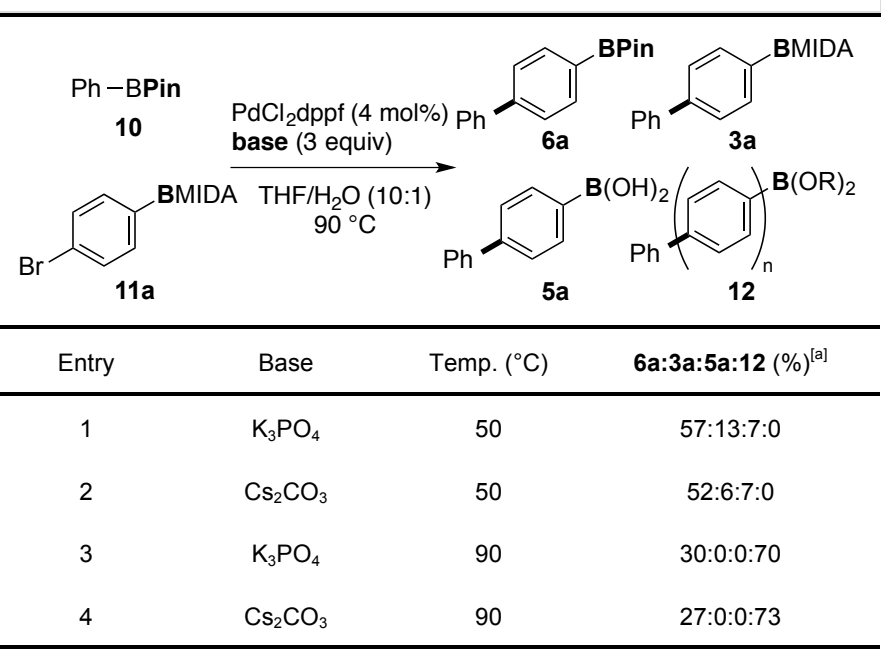

[a] Determined by HPLC analysis. 
Reactions at $50{ }^{\circ} \mathrm{C}$ and $90{ }^{\circ} \mathrm{C}$ were highly positive for both bases employed. At the more moderate $50{ }^{\circ} \mathrm{C}$ (entries 1 and 2 ), good conversion to product was observed (approx. 50\%) with some of the intermediate boron species also detected - BMIDA 3a was observed in 6-13\% with the parent boronic acid 5 a seen at $7 \%$ in both cases. Pleasingly, no oligomerization was observed but conversion was incomplete at approximately $70 \%$. Increasing the temperature of the reaction to $90{ }^{\circ} \mathrm{C}$ (entries 3 and 4) provided complete conversion of starting material, a relatively low conversion (approx. 30\%) to the desired product $6 a$, with the mass balance consisting of undefined oligomeric material (12). ${ }^{[15]}$

We believed the large degree of oligomerization was due to a more rapid hydrolysis of the BMIDA starting material 11a and/or intermediate $\mathbf{3 a}$ at this higher temperature: BMIDA compounds are readily hydrolyzed in the presence of aqueous base and this can proceed rapidly with strong bases (e.g., with $\mathrm{NaOH}$ ) or more slowly with weaker bases (e.g., with $\left.\mathrm{K}_{3} \mathrm{PO}_{4}\right) .{ }^{[4 \mathrm{e}, 5 \mathrm{~d}, \mathrm{~g}, \mathrm{q}]}$ Burke employed $\mathrm{K}_{3} \mathrm{PO}_{4}$-mediated slow hydrolysis of BMIDA as a method to facilitate the cross-coupling of notoriously sensitive boronic acids via slow-release protocol. ${ }^{[5 \mathrm{~h}, 0]}$ For the reaction in Table 1, while the conversion to product was greater at $50{ }^{\circ} \mathrm{C}$, overall conversion was greater at $90^{\circ} \mathrm{C}$. Based on this we elected to pursue optimization at $90{ }^{\circ} \mathrm{C}$ as we believed that an appropriately balanced basic biphase $\mathrm{e}^{[1 \mathrm{~d}, 1 \mathrm{e}]}$ would mitigate premature BMIDA hydrolysis and thereby eliminate the oligomerization issue.

Systematic $\mathrm{H}_{2} \mathrm{O}$ Evaluation. We first evaluated the quantity of $\mathrm{H}_{2} \mathrm{O}$ added to the reaction using $\mathrm{K}_{3} \mathrm{PO}_{4}$ as the base. In terms of hygroscopicity, $\mathrm{K}_{3} \mathrm{PO}_{4}$ is known to form a stable tetrahydrate $^{[14]}$ and so was expected to support a specific quantity of $\mathrm{H}_{2} \mathrm{O}$. However, the availability of this 'captured' $\mathrm{H}_{2} \mathrm{O}$ was unknown. In addition, based on the envisioned solution processes taking place (Scheme 1), as the reaction progresses, boric acid will accumulate and may condense to release additional $\mathrm{H}_{2} \mathrm{O} .^{[14]}$ This may be promoted by a desiccant, such as $\mathrm{K}_{3} \mathrm{PO}_{4}$. Therefore, the exact quantity of $\mathrm{H}_{2} \mathrm{O}$ available within the reaction at any stage was uncertain. As such, we undertook a comprehensive $\mathrm{H}_{2} \mathrm{O}$ evaluation (Scheme 3 and Chart 1).

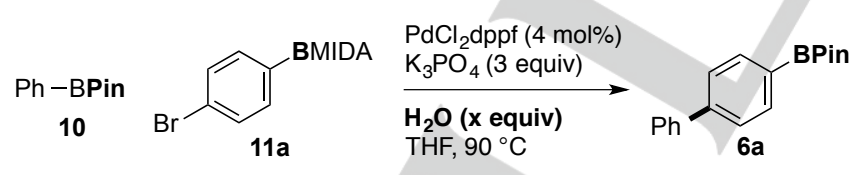

Scheme 3. Evaluation of $\mathrm{H}_{2} \mathrm{O}$ and the effect on conversion to $6 \mathbf{a}$.

As expected, the conversion to $\mathbf{6 a}$ was highly dependent on the level of $\mathrm{H}_{2} \mathrm{O}$ added to the system. The response surface in Chart 1 displayed three main regions in which the reaction could be predicted to deliver specific outputs. (1) Using 0 equivalents of $\mathrm{H}_{2} \mathrm{O}$. Cross-coupling was found to be very inefficient with only modest levels of product observed $(<60 \%)$ and extended reaction times failing to provide any increase. No oligomerization was detected and the mass balance was principally unreacted starting material.

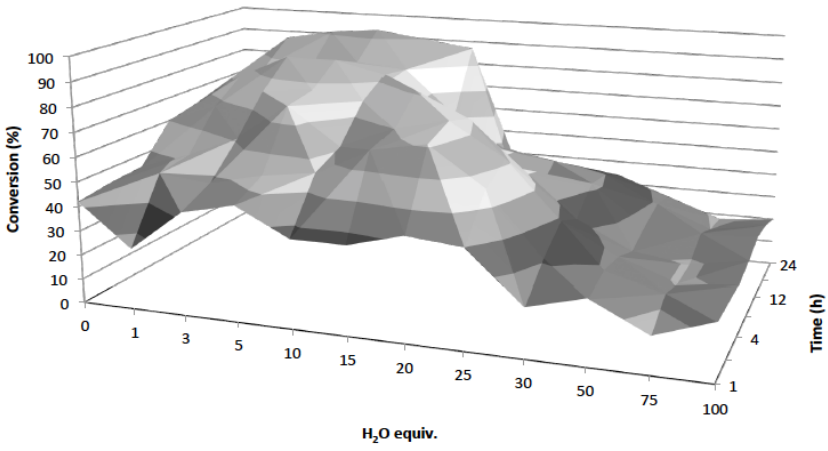

Chart 1. Experimental response surface: conversion to $6 a$ vs. $\mathrm{H}_{2} \mathrm{O}$ equivalents/time for the formal homologation. Determined by HPLC analysis.

(2) Using 1-15 equivalents of $\mathrm{H}_{2} \mathrm{O}$. When the reaction was allowed to take place over $24 \mathrm{~h}$, excellent levels of conversion to 6a could be obtained (up to $92 \%$ at 5 equivalents $\mathrm{H}_{2} \mathrm{O}$ ) with no oligomerization and complete consumption of starting material. Shorter reaction times resulted in lower conversions to $\mathbf{6 a}$ with variable levels of intermediate boron species $\mathbf{3} \mathbf{a}$ and $\mathbf{5 a}$ detected. (3) Using 15-25 equiv $\mathrm{H}_{2} \mathrm{O}$. Conversion to products, intermediates or byproducts was unpredictable and variable depending on the reaction time - shorter times appeared to enable good levels of conversion to $\mathbf{6 a}$, with oligomerization increasing markedly as the reaction time increased, potentially indicating that cross-coupling of 11a was inefficient allowing further reaction of $11 \mathbf{a}$ with $\mathbf{6 a}$ or $\mathbf{3 a}$. (4) Using $>25$ equiv $\mathrm{H}_{2} \mathrm{O}$. Poor, but consistent levels of conversion to 6a (approx. 20-30\%) were observed throughout with the mass balance composed of oligomeric material, indicating poor control of the rate of BMIDA hydrolysis.

Based on this evaluation, we selected 5 equivalents of $\mathrm{H}_{2} \mathrm{O}$ to move forward. This was chosen since it provided excellent levels of conversion as well as providing a tolerance for any additional $\mathrm{H}_{2} \mathrm{O}$ arising from a less stringent reaction set up.

Base Evaluation. With a functional knowledge of $\mathrm{H}_{2} \mathrm{O}$ influence, we next evaluated the role of the base. Different bases were predicted to exhibit broadly different impacts on the reaction. Amatore and Jutand have demonstrated the triple role of $\mathrm{HO}^{-}$in the Suzuki-Miyaura reaction, affecting oxopalladium formation, boron solution equilibria, as well as reductive elimination. ${ }^{[16]}$ These authors also demonstrated that different metal cations also affect Suzuki-Miyaura cross-coupling ${ }^{[17]}$ For the reaction under development, in addition to the expected effects detailed by Amatore and Jutand, variation of physical properties was expected to have a profound impact.

A first survey of potassium bases immediately revealed the importance of $\mathrm{pK}_{\mathrm{a}}^{\dagger}$ (Table 2 and Chart 2). Using KTFA (entry 1), no cross-coupling took place and starting materials were returned. As the $\mathrm{pK}_{\mathrm{a}}$ increased through $\mathrm{KOAc}, \mathrm{K}_{2} \mathrm{CO}_{3}$, and $\mathrm{K}_{3} \mathrm{PO}_{4}$ (entries 2-4), cross-coupling efficiency immediately improved and speciation control was also possible, with conversion reaching an optimum in the presence of $\mathrm{K}_{3} \mathrm{PO}_{4}$. 
Table 2. Potassium base survey.

\begin{tabular}{|c|c|c|c|}
\hline $\begin{array}{c}\mathrm{Ph}-\mathrm{BPin} \\
10\end{array}$ & BMIDA & $\begin{array}{l}\mathrm{PdCl}_{2} \mathrm{dppf}(4 \mathrm{~mol} \%) \\
\text { Base (3 equiv) } \\
\underset{\mathrm{H}_{2} \mathrm{O}(5 \text { equiv })}{\longrightarrow} \\
\mathrm{THF}, 90^{\circ} \mathrm{C}\end{array}$ & $6 a$ \\
\hline Entry & Base & $\mathrm{pK}_{\mathrm{a}}^{[\mathrm{a}]}$ & $6 \mathbf{a}(\%)^{[b]}$ \\
\hline 1 & KTFA & 0 & 0 \\
\hline 2 & KOAC & 6 & 37 \\
\hline 3 & $\mathrm{~K}_{2} \mathrm{CO}_{3}$ & 10 & 51 \\
\hline 4 & $\mathrm{~K}_{3} \mathrm{PO}_{4}$ & 12 & 92 \\
\hline 5 & $\mathrm{KOH}$ & 16 & 22 \\
\hline 6 & $\mathrm{KO} t-\mathrm{Bu}$ & 18 & 23 \\
\hline 7 & $\mathrm{KH}_{2} \mathrm{PO}_{4}$ & 2 & 0 \\
\hline 8 & $\mathrm{~K}_{2} \mathrm{HPO}_{4}$ & 7 & 0 \\
\hline
\end{tabular}

[a] Approximate values. ${ }^{[18]}[\mathrm{b}]$ Determined by HPLC analysis.

Starting material consumption was incomplete for KOAc and $\mathrm{K}_{2} \mathrm{CO}_{3}$. Interestingly, for entries $2-4,3 \mathrm{a}$ or $5 \mathrm{a}$ were not detected - all Suzuki-Miyaura product was converted to the BPin adduct 6a. Therefore, under specific conditions, the overall reaction efficiency becomes entirely dependent on cross-coupling efficiency. Use of $\mathrm{KOH}$ and $\mathrm{KOt}$-Bu delivered incomplete conversion of starting materials, poor conversion to product (approx. 20\%), and extensive oligomerization, presumably due to rapid hydrolysis of BMIDA (entries 5 and 6 ). The relationship between $\mathrm{pK}_{\mathrm{a}}$ and conversion to $\mathbf{6} \mathbf{a}$ is clearly demonstrated by entries 1-6.

However, the relationship between base and reaction efficiency is not so straightforward as bases of similar $\mathrm{pK}_{\mathrm{a}}$ were found to provide starkly different results. $\mathrm{KH}_{2} \mathrm{PO}_{4}$ (entry 7) of similar $\mathrm{pK}_{a}$ to KTFA, also provides no conversion. In contrast, $\mathrm{K}_{2} \mathrm{HPO}_{4}$ (entry 8) provides no conversion while this has similar $\mathrm{pK}_{\mathrm{a}}$ to KOAc, which provides $37 \%$ of $6 \mathbf{a}$. Consequently, the reaction is not solely dependent upon $\mathrm{pK}_{\mathrm{a}}$ (or the resultant solution $\mathrm{pH}$ ) although this is clearly highly important.

This was compounded when the effect of the metal countercation was evaluated. Tribasic phosphate appeared to be optimum for the reaction but the effect of variation of the associated metal ion - alkali metals or alkaline earths - was surprising (Table 3 ).

The $\mathrm{pK}_{\mathrm{a}}$ and solution $\mathrm{pH}$ ranges of these phosphate salts are approximately equivalent. Accordingly, the widely different reaction response must be due to other factors. As noted above, Amatore and Jutand have shown that the countercation can impact upon cross-coupling efficiency via influencing transmetallation. ${ }^{[17]} \mathrm{H}_{2} \mathrm{O}$ plays an important role in the transport of metal ions from the aqueous phase to the organic phase. ${ }^{[19]}$ Accordingly, the quantity of $\mathrm{H}_{2} \mathrm{O}$ present in the system may directly affect the availability of metal ions in the organic phase. This could contribute to the results observed in Table 3 .

Table 3. Tribasic phosphate countercation survey

\begin{tabular}{ccc}
\hline Entry & Base & $\mathbf{6 a}(\%)^{[a]}$ \\
\hline 1 & $\mathrm{Li}_{3} \mathrm{PO}_{4}$ & 0 \\
2 & $\mathrm{Na}_{3} \mathrm{PO}_{4}$ & 0 \\
3 & $\mathrm{~K}_{3} \mathrm{PO}_{4}$ & 92 \\
4 & $\mathrm{Cs}_{3} \mathrm{PO}_{4}$ & 0 \\
5 & $\mathrm{Mg}_{3}\left(\mathrm{PO}_{4}\right)_{2}$ & 0 \\
6 & $\mathrm{Ca}_{3}\left(\mathrm{PO}_{4}\right)_{2}$ & 0 \\
\hline
\end{tabular}

[a] Determined by HPLC analysis.

For the reaction under development, however, the physical properties of the base appear to be one of the principal contributors to reaction efficiency. Selected physical constants for the evaluated bases are provided in Table 4.

From this available data, two principal relationships can be established:

(1) The relationship between $\mathrm{pK}_{\mathrm{a}} / \mathrm{pH}$ and conversion. From the results in Table 2 and Chart 2 as well as previous studies of BMIDA cross-coupling and boronic ester esterification processes, the reaction is evidently dependent on $\mathrm{pH}$ control. An optimum is clearly reached with $\mathrm{K}_{3} \mathrm{PO}_{4}$ with an approximate $\mathrm{pK}_{\mathrm{a}}$ and $\mathrm{pH}$ range of 12.7 and 10-14, respectively. However, evaluation of different metal phosphates, which exhibit approximately similar $\mathrm{pK}_{\mathrm{a}}$ and $\mathrm{pH}$ shows that $\mathrm{K}_{3} \mathrm{PO}_{4}$ is exclusively effective while the other phosphates result in no conversion to the desired product - indeed, no cross-coupling at all under the same reaction conditions.

Solvation effects driven by the electrostatic parameter result in aqueous solutions of metal ions varying markedly in their $\mathrm{pH}$, from 11.2-14 for the ions employed in Table $4 .{ }^{[14]}$ The more acidic cations, such as $\mathrm{Mg}^{2+}$ or $\mathrm{Ca}^{2+}$, may therefore result

Table 4. Selected physical constants for the bases used in Tables 2 and 3.

\begin{tabular}{llllll}
\hline Entry & Base & $\mathrm{pK}_{\mathrm{a}}^{[\mathrm{a}]}$ & $\begin{array}{l}\text { Approx. pH } \\
\text { of aqueous } \\
\text { metal ion }\end{array}$ & $\begin{array}{l}\text { Solubility at } \mathrm{RT} \\
(\mathrm{g} / 100 \mathrm{~mL} \\
\left.\mathrm{H}_{2} \mathrm{O}\right)^{[\mathrm{b}]}\end{array}$ & $\begin{array}{l}6 \mathbf{6 a} \\
(\%)^{[\mathrm{c}]}\end{array}$ \\
\hline 1 & $\mathrm{Li}_{3} \mathrm{PO}_{4}$ & 12.7 & 13.6 & 0.027 & 0 \\
2 & $\mathrm{Na}_{3} \mathrm{PO}_{4}$ & 12.7 & 13.9 & 14.25 & 6 \\
3 & $\mathrm{~K}_{3} \mathrm{PO}_{4}$ & 12.7 & 14.0 & 106 & 92 \\
4 & $\mathrm{Cs}_{3} \mathrm{PO}_{4}$ & 12.7 & --- & -- & 6 \\
5 & $\mathrm{Cs}_{2} \mathrm{CO}_{3}$ & 10.3 & --- & 261 & 0 \\
6 & $\mathrm{Mg}_{3}\left(\mathrm{PO}_{4}\right)_{2}$ & 12.7 & 11.2 & $0.0009^{[\mathrm{d}]}$ & 0 \\
7 & $\mathrm{Ca}_{3}\left(\mathrm{PO}_{4}\right)_{2}$ & 12.7 & 12.7 & 0.00012 & 0
\end{tabular}




\begin{tabular}{llllll}
8 & $\mathrm{KTFA}$ & -0.25 & 14.0 & -- & 0 \\
9 & $\mathrm{KOAC}$ & 4.8 & 14.0 & 269 & 37 \\
10 & $\mathrm{~K}_{2} \mathrm{CO}_{3}$ & 10.3 & 14.0 & 111 & 51 \\
11 & $\mathrm{KOH}$ & 14.2 & 14.0 & 121 & 22 \\
12 & $\mathrm{KOt}-\mathrm{Bu}$ & 17.0 & 14.0 & --- & 23 \\
13 & $\mathrm{KH}_{2} \mathrm{PO}_{4}$ & 2.1 & 14.0 & 25 & 0 \\
14 & $\mathrm{~K}_{2} \mathrm{HPO}_{4}$ & 7.2 & 14.0 & 168 & 0 \\
\hline
\end{tabular}

[a] Approximate values. ${ }^{[18]}$. [b] Approximate values. ${ }^{[14]}$. [c] Determined by HPLC analysis using an internal standard. [d] Value for the pentahydrate.

in a buffering effect and thereby negatively modulate $\mathrm{pH}$, however, this is likely to be minor in contrast to the $\mathrm{pH}$ contribution of the anion and does not account for the complete absence of reactivity seen. For example, KOAc delivers a considerably lower solution $\mathrm{pH}$ than $\mathrm{Mg}_{3}\left(\mathrm{PO}_{4}\right)_{2}$, however, $\mathrm{KOAc}$ does deliver some observable cross-coupling and speciation control while this is completely absent for $\mathrm{Mg}_{3}\left(\mathrm{PO}_{4}\right)_{2}$ (entry 6 vs. entry 9). Accordingly, other properties of the bases must be considered in conjunction with $\mathrm{pH}$ to explain these observations. (2) The relationship between solubility of the base and conversion. Information on the hygroscopicity of the bases in Table 4 is generally only qualitative: these are typically designated as either hygroscopic or deliquescent with little quantitative information available. Some salts have specific hydrate states, such as $\mathrm{K}_{3} \mathrm{PO}_{4}$ and $\mathrm{Mg}_{3}\left(\mathrm{PO}_{4}\right)_{2}$ existing as the stable tetrahydrate and octahydrate, respectively. ${ }^{[14]}$ In terms of the saturated aqueous solutions, relative humidity $(\% \mathrm{RH})$ as well as the more appropriate relative saturation (\%RS) values have not been documented for all of these bases. Indeed, only KOAc, $\mathrm{K}_{2} \mathrm{CO}_{3}$, and $\mathrm{KOH}$ have $\% \mathrm{RH}$ available $-23.1 \%, 43.2 \%, 9.3 \%$ (at $20{ }^{\circ} \mathrm{C}$ ), respectively. ${ }^{[20]}$ Accordingly, establishing a relationship between reaction efficiency and hygroscopicity was not possible. However, solubility data was informative. Specifically, as the aqueous solubility of the base increases, conversion also increases. For example, when comparing the alkali metal and alkaline earth phosphates, moving from $\mathrm{Ca}^{2+}$ to $\mathrm{Mg}^{2+}$ to $\mathrm{Li}^{+}$to

Table 5. Increasing the quantity of $\mathrm{H}_{2} \mathrm{O}$ with alkali metal phosphate bases.

\begin{tabular}{|c|c|c|}
\hline $\begin{array}{c}\mathrm{Ph}-\mathrm{BPin} \\
10\end{array}$ & $\begin{array}{l}\text { ff (4 mol\%) } \\
\text { equiv) } \\
\text { quiv) } \\
\mathrm{C}\end{array}$ & 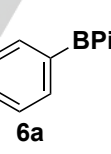 \\
\hline Entry & $\mathrm{H}_{2} \mathrm{O}$ equiv & $\mathbf{6 a}(\%)^{[\mathrm{a}]}$ \\
\hline 1 & 22 equiv & 0 \\
\hline 2 & 50 equiv & 8 \\
\hline 3 & 22 equiv & 16 \\
\hline 4 & 50 equiv & 20 \\
\hline 5 & 22 equiv & 30 \\
\hline
\end{tabular}

\begin{tabular}{cccc}
6 & $\mathrm{~K}_{3} \mathrm{PO}_{4}$ & 50 equiv & 26 \\
7 & $\mathrm{Cs}_{3} \mathrm{PO}_{4}$ & 22 equiv & 8 \\
8 & $\mathrm{Cs}_{3} \mathrm{PO}_{4}$ & 50 equiv & 6 \\
\hline
\end{tabular}

[a] Determined by HPLC analysis using an internal standard.

$\mathrm{Na}^{+}$to $\mathrm{K}^{+}$, both solubility and conversion increase (entries 1-3, 6, and 7). Unfortunately, no solubility data was available for $\mathrm{Cs}_{3} \mathrm{PO}_{4}$. If solubility is removed as a factor then $\mathrm{pH}$ drives the reaction efficiency. For example, $\mathrm{K}_{2} \mathrm{CO}_{3}$ and $\mathrm{Cs}_{2} \mathrm{CO}_{3}$ both exhibit good solubility $(>1 \mathrm{~g} / \mathrm{mL})$ and equivalent $\mathrm{pH}$ and deliver very similar levels of conversion (approx. 50\%). KOAc again demonstrates good solubility but with a lower $\mathrm{pH}$, conversion decreases (entry 9).At the low quantity of $\mathrm{H}_{2} \mathrm{O}$ used in this system (5 equiv), low base solubility appears to be a key issue. We considered the possibility that this may be rectified if the quantity of $\mathrm{H}_{2} \mathrm{O}$ was increased. Indeed, analysis of the reactions of the alkali metal phosphates at 22 equiv $\mathrm{H}_{2} \mathrm{O}\left(10: 1 \mathrm{THF}: \mathrm{H}_{2} \mathrm{O}\right)$ and 50 equiv $\mathrm{H}_{2} \mathrm{O}$ shows that bases of lower solubility can begin to deliver some improved conversion in certain cases (Table 5). For example, $\mathrm{Li}_{3} \mathrm{PO}_{4}$ starts to show some $\mathrm{C}-\mathrm{C}$ bond formation as well as speciation control at 50 equiv $\mathrm{H}_{2} \mathrm{O}$ (Table 5 , entry 2 ) and $\mathrm{Na}_{3} \mathrm{PO}_{4}$ improves from $6 \%$ (Table 4 , entry 2 ) to $20 \%$ conversion to 6 a when increasing the $\mathrm{H}_{2} \mathrm{O}$ quantity 10 -fold (Table 5 , entry 4). Conversely, control is rapidly lost in the reactions with $\mathrm{K}_{3} \mathrm{PO}_{4}$ using excesses of $\mathrm{H}_{2} \mathrm{O}$ (Table 5 , entries 5 and 6 vs. Table 4 , entry 3 ), leading to extensive uncontrolled oligomerization, while $\mathrm{H}_{2} \mathrm{O}$ loading had little effect on reactions using $\mathrm{Cs}_{3} \mathrm{PO}_{4}$ (entries 7 and 8).

Overall, $\mathrm{pH}$ and solubility of the base are the primary factors responsible for control over the formal homologation reaction. When solubility is good, appropriate $\mathrm{pH}$ modulation then ensures effective control of the speciation events, with $\mathrm{K}_{3} \mathrm{PO}_{4}$ providing an ideal balance of both of these properties that allows efficient $\mathrm{C}-\mathrm{C}$ bond formation and hydrolysis/esterification. There may be a 'threshold solubility' for a specific base $\mathrm{pK}_{\mathrm{a}}$ in order to ensure reaction efficiency; however, this could not be established from the available data.

Catalyst and Electrophile Evaluation. Following optimization of $\mathrm{H}_{2} \mathrm{O}$ and base, we subsequently performed a thorough analysis of reaction performance in relation to the catalyst and electrophile. From the preceding optimization phase, we were aware that, under specific conditions, the overall reaction efficiency became dependent upon the cross-coupling efficiency, i.e., that speciation events could be readily controlled and all available initial cross-coupling product $\mathbf{3 a}$ could be smoothly funneled to $6 \mathrm{a}$. To ensure a robust $\mathrm{C}-\mathrm{C}$ bond formation, we analyzed a range of catalyst systems under the emerging optimum base $/ \mathrm{H}_{2} \mathrm{O}$ conditions (Table 6).From these results, it was clear that use of $\mathrm{Pd}(\mathrm{II})$ precatalysts was preferred over $\operatorname{Pd}(0)$ (for example, entry 4 vs. entry 5 ). In addition, the reaction clearly requires a phosphine ligand in order to be synthetically useful and, in the majority of cases, $\mathrm{Pd}(\mathrm{OAc})_{2}$ was superior to $\mathrm{PdCl}_{2}$. In the absence of a ligand (entries 1-3), very poor cross- 
coupling was observed. However, not all phosphine ligands were effective in promoting $\mathrm{C}-\mathrm{C}$ bond formation under the conditions employed. For simple ligands, the reaction performance was generally greater when the catalyst was preformed - addition of separate Pd(II) source and ligand was often less effective than use of the same preformed catalyst. For example, addition of $\mathrm{PPh}_{3}$ to $\mathrm{PdCl}_{2}$ delivered approximately the same conversion to $6 \mathrm{a}$ as the preformed $\mathrm{PdCl}_{2}\left(\mathrm{PPh}_{3}\right)_{2}$ (entry 5 vs. entry 7) whereas, addition of dppf to $\mathrm{PdCl}_{2}$ was significantly less effective than use of the preformed $\mathrm{PdCl}_{2} \mathrm{dppf}$ (entry 6 vs. entry 15). Use of more active catalyst systems such as the biaryl monophosphines developed by Buchwald, ${ }^{[21]}$ gave good results but were less effective for bromophenyl BMIDA substrate 11a than the simpler $\mathrm{PdCl}_{2} \mathrm{dppf}$ (entry 6 vs. entries 21-28).

Table 6. Catalyst evaluation for the reaction of 10 and 11.

$\underset{10}{\mathrm{Ph}-\mathrm{BPin}}$

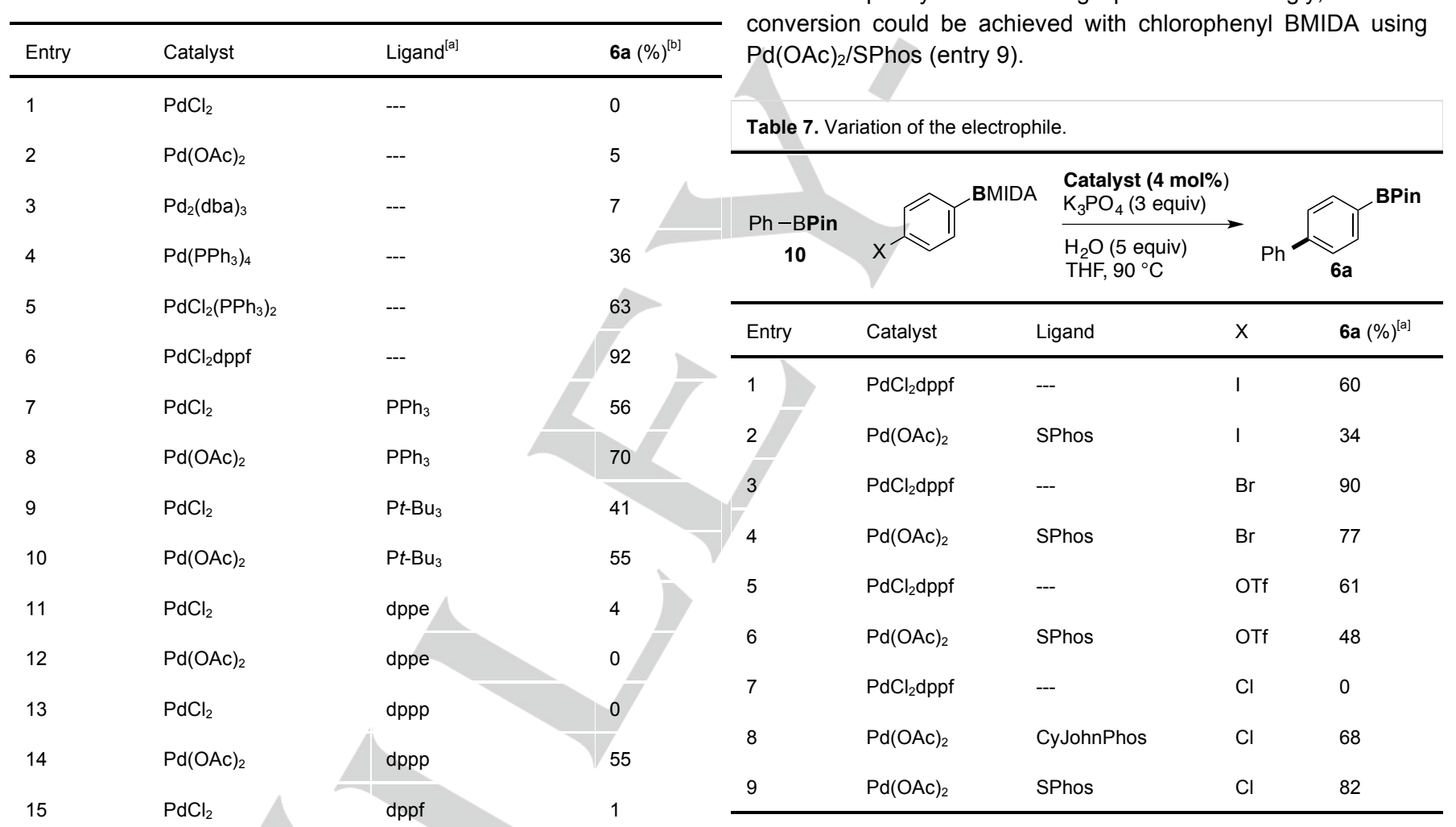

$\begin{array}{llll}15 & \mathrm{PdCl}_{2} & \mathrm{dppf} & 1 \\ 16 & \mathrm{Pd}(\mathrm{OAc})_{2} & \mathrm{dppf} & 24 \\ 17 & \mathrm{PdCl}_{2} & \text { BINAP } & 13 \\ 18 & \mathrm{Pd}(\mathrm{OAc})_{2} & \text { BINAP } & 67 \\ 19 & \mathrm{PdCl}_{2} & \text { XantPhos } & 0 \\ 20 & \mathrm{Pd}(\mathrm{OAc})_{2} & \text { XantPhos } & 10 \\ 21 & \mathrm{PdCl}{ }_{2} & \text { SPhos } & 14 \\ 22 & \mathrm{Pd}(\mathrm{OAc})_{2} & \text { SPhos } & 77\end{array}$

\begin{tabular}{llll}
23 & $\mathrm{PdCl}_{2}$ & XPhos & 20 \\
24 & $\mathrm{Pd}(\mathrm{OAc})_{2}$ & XPhos & 67 \\
25 & $\mathrm{PdCl}_{2}$ & CyJohnPhos & 4 \\
26 & $\mathrm{Pd}(\mathrm{OAc})_{2}$ & CyJohnPhos & 72 \\
27 & $\mathrm{PdCl}_{2}$ & DavePhos & 23 \\
28 & $\mathrm{Pd}(\mathrm{OAc})_{2}$ & DavePhos & 71 \\
\hline
\end{tabular}

[a] Added independently. [b] Determined by HPLC analysis.

To ensure synthetic scope, an analysis of halide and pseudohalide derivatives of 11a was conducted with the most successful catalyst $\left(\mathrm{PdCl}_{2} \mathrm{dppf}\right)$ as well as a more activated $\mathrm{Pd}(\mathrm{OAc})_{2} /$ monophosphine-based catalyst system (Table 7). With the exception of the less reactive chlorophenyl BMIDA substrate (entries 7-9), $\mathrm{PdCl}_{2} \mathrm{dppf}$ provided superior levels of conversion, with bromophenyl BMIDA being optimum. Pleasingly, excellent conversion could be achieved with chlorophenyl BMIDA using $\mathrm{Pd}(\mathrm{OAc})_{2} /$ SPhos (entry 9).

\footnotetext{
[a] Determined by HPLC analysis.
}

\section{Substrate Scope.}

The scope of the optimized reaction conditions was explored through the synthesis of a range of substrates (Figure 2). ${ }^{[9]}$

A broad range of common and synthetically useful functionality was tolerated including amides $(\mathbf{6 b})$, esters $(\mathbf{6 e}, \mathbf{6 n})$, ethers $(\mathbf{6} \mathbf{h})$, and nitriles $(\mathbf{6 g})$, encompassing both electron-rich and electron-poor BPin starting materials. Pleasingly, the reaction also tolerated heterocyclic moieties, such as pyrazoles, furans, pyrans, and thiophenes $(\mathbf{6} \mathbf{d}, \mathbf{6 i}, \mathbf{6 k}, \mathbf{6 m})$. All three 
substitution patterns on the haloaryl MIDA were compatible, although ortho-substitution was more effective with less sterically demanding BPins. For these reaction conditions, fluoro-substituted BMIDA esters were found to be amenable but other functionalization of the BMIDA component was less successful. This could be overcome by the use of a more active catalyst system (vide infra).

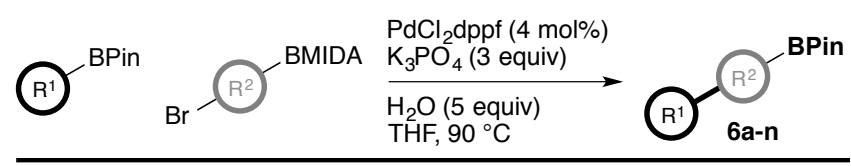<smiles>FC(=Nc1ccc(-c2ccc(Cc3ccccc3)cc2)cc1)c1ccccc1</smiles><smiles>COC(=O)C1(c2ccc(-c3ccc(Br)cc3)cc2)CC1</smiles>
6c: $72 \%$ 6d: $66 \%$ 6e: $83 \%$<smiles>Brc1ccccc1C=Cc1ccccc1</smiles><smiles>CC(C)(C)ON(c1cccc(-c2ccc(Br)c(C(=O)c3ccccc3)c2)c1)C(C)(C)C</smiles><smiles>FC(F)(F)Oc1ccc(-c2cccc(Cc3ccccc3)c2)cc1</smiles><smiles>[124OH]</smiles><smiles>Cn1cc(-c2ccccc2Br)cn1</smiles>

6i: $69 \%$
$\left(\mathrm{Pd}(\mathrm{OAc})_{2} / \mathrm{SPhos}\right)$ easily circumvented this reactivity issue, allowing these less reactive electrophiles to be effectively crosscoupled as well as preserving the speciation control. This enabled the use of haloaryl BMIDA esters with $\mathrm{CF}_{3}(6 \mathbf{6}, \mathbf{6 q})$ and OMe (6r) functionality as well heterocyclic BMIDA esters (6p). Certain functionality, however, in particular o-OMe $(6 \mathbf{6}, 6 \mathbf{t})$ and $\mathrm{o}-\mathrm{CO}_{2} \mathrm{Me}(6 \mathbf{u}, 6 \mathbf{v})$, were not tolerated (vide infra).

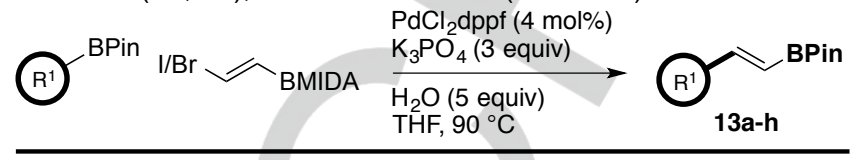<smiles>Fc1ccc(/C=C/[Pb]c2ccccc2)c(F)c1</smiles><smiles>Cc1noc(C)c1/C=C/Cc1ccccc1</smiles><smiles>C=C(Br)c1ccccc1</smiles>

13g: $52 \%[a]$<smiles>C(C=Cc1ccccc1)=Cc1ccccc1</smiles>

13h: $0 \%$
Figure 3. Using alkenyl BMIDA boronic esters. Yields of isolated products. [a] As a mixture of olefin regioisomers and stereoisomers.<smiles>Cc1ccc(Cc2cccc(Cc3ccccc3)c2)cc1</smiles>
6j: $85 \%$ 6k: $88 \%$ BPin<smiles>Brc1ccccc1-c1coc(-c2ccccc2)c1</smiles><smiles>CC(=O)Cc1ccc(-c2cccc(Cc3ccccc3)c2)cc1</smiles>

Figure 2. Formal homologation of Ar-BPin using haloaryl BMIDA esters. Yields of isolated products.

The homologation process was also found to be immediately transferable to haloalkenyl BMIDA reagents (Figure 3 ). ${ }^{[9]}$ This enabled the preparation of a set of elaborated alkenes that included both aryl (13c, 13e, 13g) and heteroaryl (13a, 13b, 13d, 13f) substituents. While 1,2-disubstituted haloalkenyl BMIDA components were broadly successful, the use of 1,1 disubstituted olefins led to isomerization providing mixtures of 1,1- and 1,2-disubstituted olefinic BPin products $(\mathbf{1 3 g}) .{ }^{[5 \mathrm{~h}]}$ Unfortunately, dienyl BPin products could not be prepared using this protocol (13h).

To further broaden the scope of the reaction, a set of functionalized haloaryl BMIDAs was employed (Figure 4). ${ }^{[9]}$ For these substrates the standard catalyst system ( $\left.\mathrm{PdCl}_{2} \mathrm{dppf}\right)$ was not sufficiently reactive to promote efficient $\mathrm{C}-\mathrm{C}$ bond formation. However, use of a more reactive catalyst system

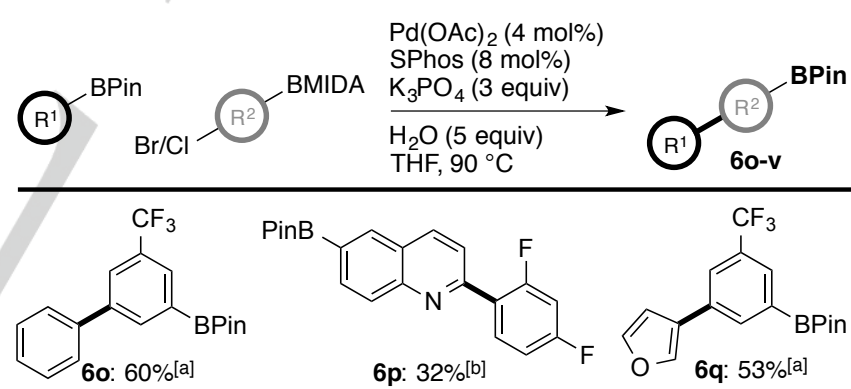<smiles>COc1cc(CC(C)=O)cc(-c2ccc(Cc3ccccc3)cc2)c1</smiles><smiles>COC(=O)c1cc(-c2ccc(OC(F)(F)F)cc2)ccc1Br</smiles><smiles>COC(=O)c1cc(-c2cccnc2)ccc1Br</smiles>

Figure 4. Homologation employing chloroaryl BMIDA and specific substituted aryl BMIDA components. Yields of isolated products. [a] Using bromoaryl BMIDA. [b] Using chloroaryl BMIDA.

The generality of the overall reaction with regards to speciation control was also assessed using three different boron 
species (Scheme 4). As shown above, the model BPin system is readily controlled under the optimized conditions to enable the formal BPin homologation process: $88 \%$ isolated yield of $\mathbf{6 a}$. Changing the starting boron species to both boronic acids and boronic acid catechol esters (BCat) was found to be relatively well accommodated using these conditions to provide access to the expected formally homologated adducts 14 and $\mathbf{1 5}$, respectively, without any further optimization. It should be noted that the low conversion to $\mathbf{1 5}$ was due to the stability of the catechol ester, which was found to readily hydrolyze to the boronic acid. These processes demonstrate the promising generality of speciation control to facilitate access to higher homologues of boron species in a one-pot operation.
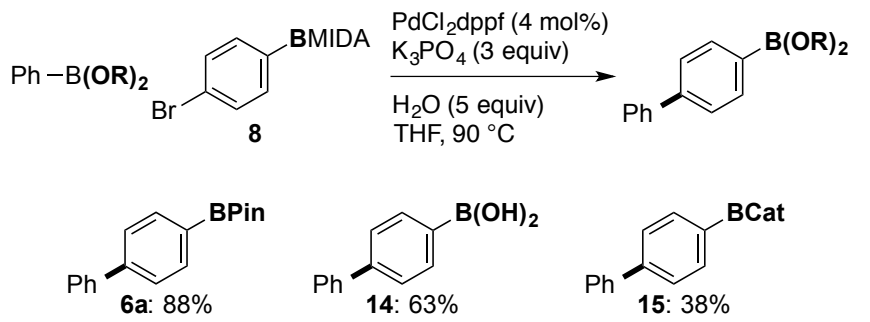

Scheme 4. Generality of speciation control using different boron species. Cat catecholate.

(a) One-pot double Suzuki-Miyaura reactions

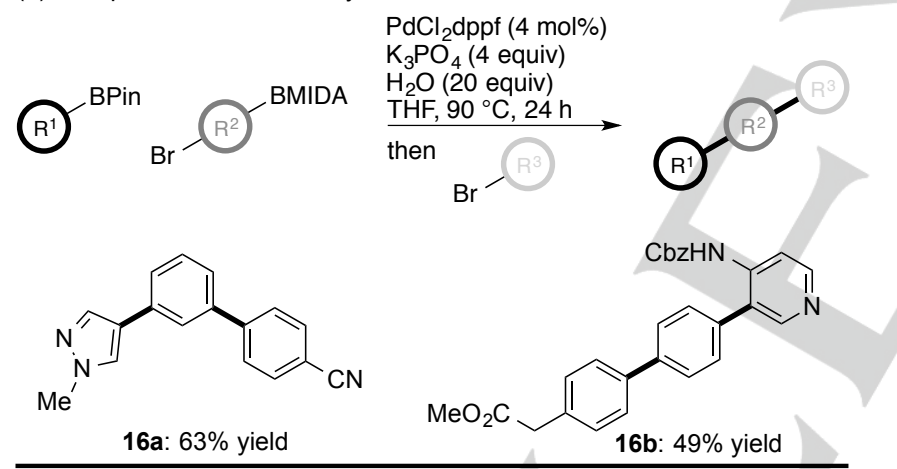

(b) One-pot double formal homologation reactions

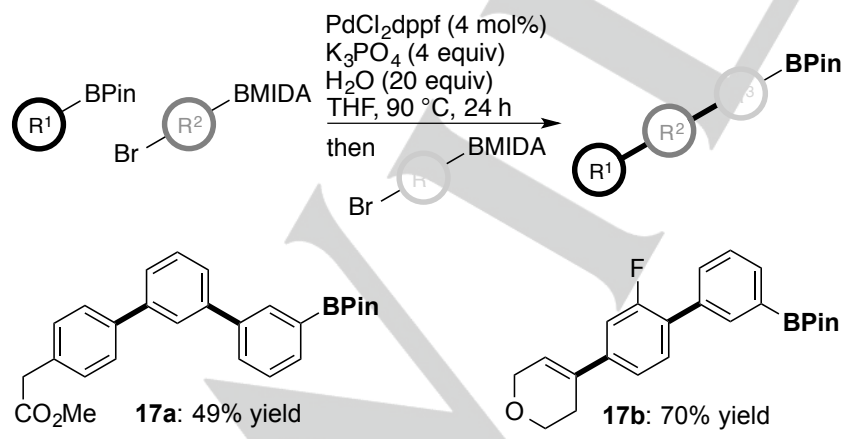

Scheme 5. One-pot double Suzuki-Miyaura and double formal homologation reactions. Yields of isolated products.

To probe whether the $\mathrm{Pd}$ catalyst remained active, after completion of the formal BPin homologation, a second aryl bromide was added to the reaction mixture (Scheme 5a). ${ }^{[9]}$ Pleasingly, the catalyst was found to be sufficiently active to enable a second Suzuki-Miyaura cross-coupling to take place between the newly formed BPin species and the added aryl bromide. This provided a method for one-pot double SuzukiMiyaura cross-coupling proceeding in good yield for products $16 \mathrm{a}$ and $\mathbf{1 6 b}$. Moreover, if a second equivalent of bromoaryl BMIDA was added, the formal homologation reaction could be extended further (Scheme $5 b$ ). ${ }^{[9]}$ Pinacol turnover could be conducted once again in this one-pot reaction now enabling a method for controlled oligomerization of BPin species, again in good yield for products $17 \mathrm{a}$ and $17 \mathrm{~b}$.

Speciation Control via Temperature Regulation. During the course of the optimization process, the effect of temperature on both the cross-coupling and speciation turnover was investigated. While $90{ }^{\circ} \mathrm{C}$ was found to be efficient at enabling conversion to product $\mathbf{6 a}$, lower temperatures gave much lower conversion (Scheme 6, Chart 2).

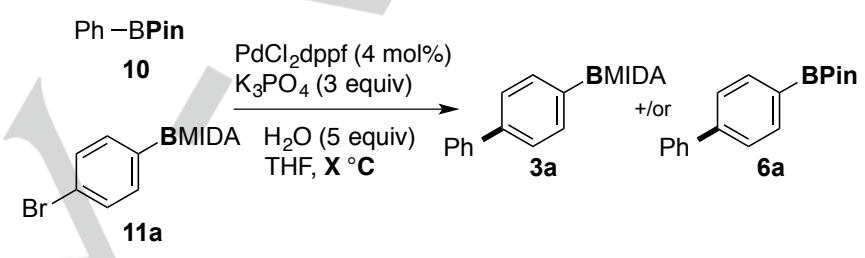

Scheme 6. Evaluation of reaction temperature during Suzuki-Miyaura crosscoupling of Ar-BPin and haloaryl BMIDA. See Chart 3, below.

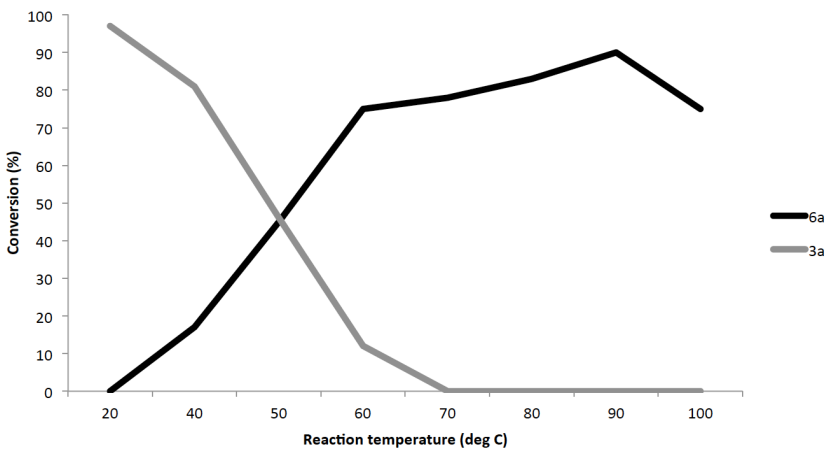

Chart 2. Temperature dependent control of speciation during Suzuki-Miyaura cross-coupling of Ar-BPin and haloaryl BMIDA. Determined by HPLC analysis.

However, it was noted that although conversion to $\mathbf{6 a}$ was decreased at lower temperature, the mass balance of the reaction was the product of the initial cross-coupling, specifically the biphenyl BMIDA species 3a. Indeed, at room temperature, 3a was found to be the sole product of the reaction. This demonstrated that, in the absence of a thermal driving force, the availability of aqueous base was sufficiently retarded under the developed conditions to ensure the integrity of BMIDA ester 3a. Upon heating, $3 a$ is hydrolyzed to boronic acid 13 , allowing conversion to $\mathbf{6 a}$. Unlike BMIDA esters, BPin esters are not easily hydrolyzed under the prevailing hydrolytic conditions. ${ }^{[2]}$ 
Accordingly, $\mathbf{6} \mathbf{a}$ is thermodynamically more stable under the basic reaction conditions.

This was readily demonstrated in a control reaction where carrying out the optimized reaction at room temperature led to $97 \%$ of $3 \mathrm{a}$ which, upon heating to $90{ }^{\circ} \mathrm{C}$, was smoothly converted to 6 a (Scheme 7).

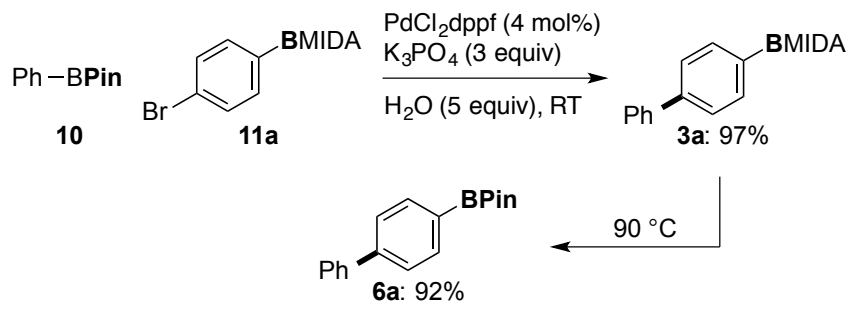

Scheme 7. Temperature control of speciation. Determined by HPLC analysis.

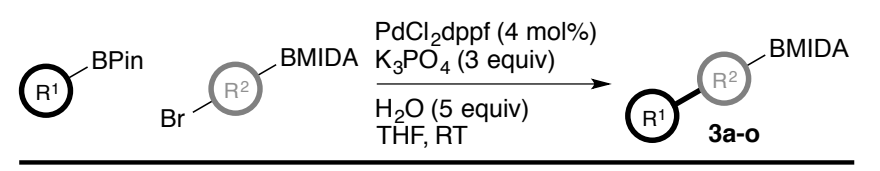<smiles>CC(C)(C)c1cc2cc(-c3ccccc3)ccc2s1</smiles><smiles>CC(C)(C)C=Cc1ccc(C(=O)OC(C)(C)C)s1</smiles><smiles>CC(C)(C)OC(=O)c1ccc(C2=CCN(C(C)(C)C)CC2)cc1</smiles>
3g: $80 \%$ 3h: $52 \%[a]$ 3i: $69 \%$<smiles>CC(C)(C)c1ccc(-c2ccccc2)s1</smiles><smiles>Cc1ccc(-c2ccc(Br)c(F)c2)cc1</smiles><smiles>N#CC(=O)OCc1cccc(-c2ccccc2F)c1</smiles>
3m: $93 \%$<smiles>Ic1ccc(-c2cccc(I)c2)cc1</smiles>

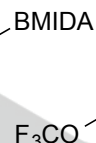
3n: $83 \%$<smiles>Cc1ccccc1-c1ccccc1</smiles>

3o: $84 \%$

Figure 5. Room temperature cross-coupling of haloaryl BMIDA in the presence of aqueous base. Yields of isolated products.

Accordingly, it became possible to chemoselectively control the outcome of the haloaryIBMIDA cross-coupling reaction reaction in terms of two possible boron species, BMIDA $\mathbf{3 a}$ or BPin $\mathbf{6 a}$, entirely through temperature control. The ability to control the product of this reaction by simply altering the temperature opened up a potentially useful synthetic possibility. Due to their rapid hydrolysis with aqueous base, cross-coupling

of haloaryl BMIDA esters is normally carried out under strictly anhydrous conditions, often employing elevated temperatures or alternate promoters such as $\mathrm{F}^{-}$to ensure synthetic efficiency. ${ }^{[4]}$ However, overly harsh thermal promotion can limit the potential scope of these processes due to conflicting decomposition pathways of sensitive substrates, including promoting protodeboronation of the boron-derived coupling partners. ${ }^{[23]}$ The ability to carry out cross-couplings of haloaryl BMIDA species at ambient temperature in the presence of aqueous base may therefore be desirable. With no further optimization required, we then sought to demonstrate the utility of this reaction by generating a small library of functionalized BMIDA products (Figure 5).

Once again a range of common functionality was compatible with the developed process. In addition, this protocol readily accommodated temperature-sensitive functional groups such as heterocyclic BMIDA (3b, 3d, $\mathbf{3} \mathbf{h}, \mathbf{3} \mathbf{j})$ and protecting groups $(\mathbf{3 e}$, $3 \mathbf{h}, 3 \mathbf{n}$ ), which were found to protodeboronate or hydrolyze, respectively, at more elevated temperatures.

It is worthwhile noting that this procedure had the added benefit of requiring very little purification - no chromatography was necessary with products isolated following a single aqueous wash and precipitation of the product using $\mathrm{Et}_{2} \mathrm{O}$. If reactions do not proceed to completion, separation of two different BMIDAs, either via crystallization or chromatography, is exceptionally difficult. Beyond the examples given in Figure 5, many similar cross-couplings do proceed effectively to deliver the product in good yield but in approx. 90\% purity. Alkenyl BPin were also readily employed, with the synthesis of a set of vinyl MIDAs including aryl (18a, 18b, 18d), heterocyclic (18c, 18e), and dienyl (18f) functionality (Figure 6).
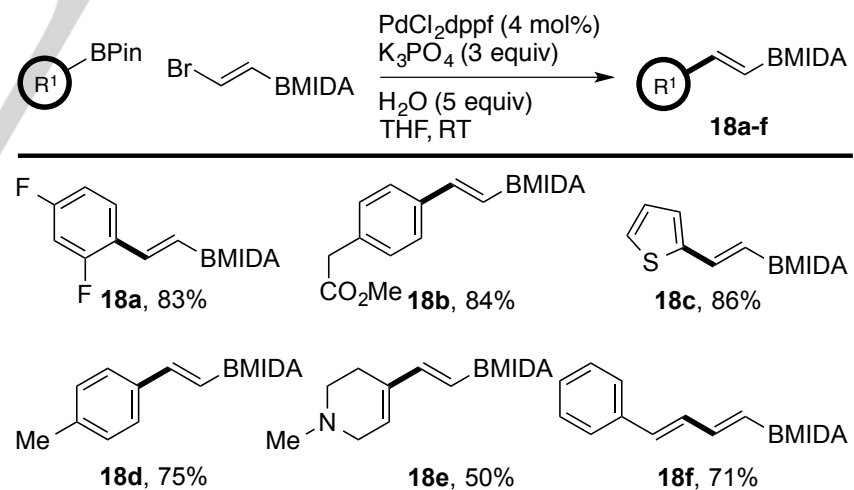

Figure 6. Room temperature cross-coupling of haloalkenyl BMIDA in the presence of aqueous base. Yields of isolated products.

From the utility perspective, the developed method compares favorably with existing methods. A comparison of reaction performance with the developed room temperature protocol vs. previously described methods ${ }^{[4 b]}$ using five representative substrates (aryl, heteroaryl, alkenyl and with variation of regiochemistry) is provided in Table 8. 
Table 8. Comparison of similar procedures for retaining the BMIDA functionality during Suzuki-Miyaura cross-coupling.

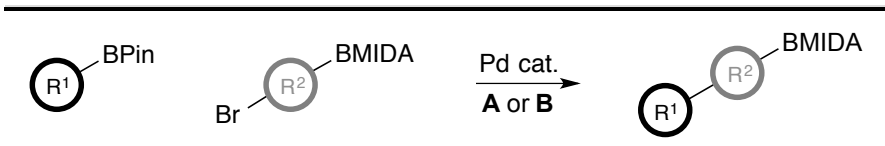

Reactions conditions

A: $\mathrm{PdCl}_{2} \mathrm{dppf}$ (4 mol\%), $\mathrm{K}_{3} \mathrm{PO}_{4}$ (3 equiv), $\mathrm{H}_{2} \mathrm{O}$ (5 equiv), THF, $\mathrm{RT}$ B: $\mathrm{PdCl}_{2} \mathrm{dppf}(5 \mathrm{~mol} \%), \mathrm{K}_{3} \mathrm{PO}_{4}$ (6 equiv), DMSO, $45^{\circ} \mathrm{C}$

Entry

[a] Yields of isolated products. [b] No coupling observed, BMIDA starting material returned. Pyranyl BPin observed to rapidly decompose at the temperature associated with conditions B. [c] No coupling observed, BMIDA starting material returned. [d] Reaction did not proceed to completion.

The mild room temperature protocol provided consistently useful yields of the desired BMIDA products (conditions A). In some cases, the previously described protocol (conditions $B$ ) was comparable (entries 1 and 2). In other cases, conditions $B$ provided low yields of the desired product (entry 5 ) or no product at all (entries 3 and 4). Lack of product using the conventional protocol could be attributed mainly to the stability of either the starting materials $(\mathbf{3 c}, \mathbf{3} \mathbf{j})$ or product $(\mathbf{3} \mathbf{j})$ for which protodeboronation was a significant issue, even at the very moderately elevated reaction temperature.

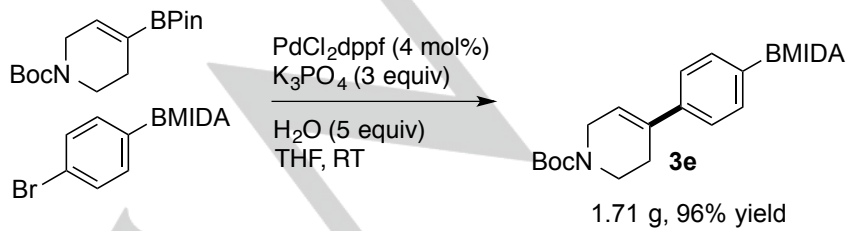

Scheme 8. Room temperature cross-coupling of haloalkenyl BMIDA in the presence of aqueous base on gram scale. Yield of isolated product.
Lastly, the room temperature procedure was also found to be readily scalable and the product can be straightforwardly isolated without resorting to chromatography (Scheme 8).

Rationalization of Anomalous Observations. 1. Efficiency of Cross-coupling: Regioisomer Disparity. During the course of substrate application for the room temperature BMIDA crosscoupling studies above, we observed a reactivity difference with the regioisomers of bromophenyl BMIDA (11a, 11b, and 11c, Figure 7). Specifically, in several cases we observed the efficiency of the cross-coupling of the meta-isomer $11 \mathrm{~b}$ to be noticeably lower than that of $11 \mathrm{a}$ and $11 \mathrm{c}$, and that this was independent of the BPin coupling partner.

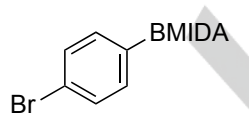

11a

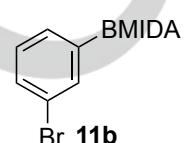

$\mathrm{Br}$ 11b

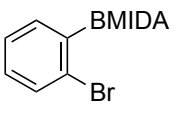

$11 \mathrm{c}$
Figure 7. Regioisomeric bromophenyl BMIDA.

Following NMR analysis, Burke noted that the BMIDA motif is neither a strongly electron-donating nor electron-withdrawing functional group. ${ }^{[4 b]}$ Based on this preceding analysis, the disparity in the efficiency of cross-coupling of 11a-c analogues was unlikely to be electronic in nature, i.e., that the dissimilarity was unlikely to be driven by large variation in the rates of oxidative addition of the regioisomeric bromides. ${ }^{[24]}$ Analysis of the ${ }^{13} \mathrm{C}$ NMR spectra of $11 \mathrm{a}-\mathrm{c}$ as an indication of relative electronic disposition of the bromide-bearing carbon, revealed that the para- and meta-isomers, $\mathbf{1 1 a}$ and $\mathbf{1 1 b}$, were very similar but that the ortho-isomer $11 \mathrm{c}$ was the electronic outlier based on the large downfield shift of this signal (124.4 ppm for 11a, 123.3 ppm for 11b, and $128.7 \mathrm{ppm}$ for 11c).

Based on this NMR analysis, it may be predicted that, amongst these regioisomers, 11c would have been most likely to exhibit a different reactivity profile. Similarly, the crystal structure data of 11a, 11b, and 11c suggests that 11c would potentially experience the largest issue with reactivity due to the proximity of the bulky BMIDA while 11a and 11b would be relatively much more accessible (Figure 8 ).

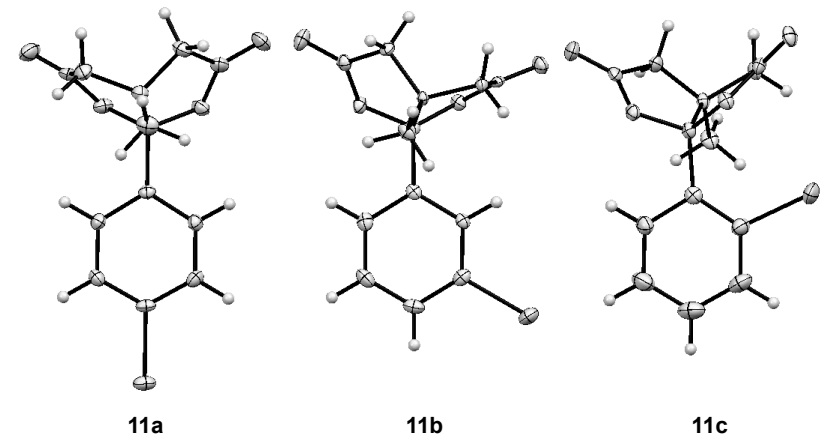

Figure 8. Selected poses of the crystal structures of 11a, 11b, and 11c. For full details, see the Supporting Information. 
Interestingly, the C-C-B bond angle for $11 \mathrm{a}$ and $11 \mathrm{~b}$ was $\sim 122^{\circ}$ but $\sim 128^{\circ}$ for $11 \mathrm{c}$, highlighting the nature of the steric environment of the $\mathrm{C}-\mathrm{Br}$ bond in 11c.

Based on these overall stereoelectronic considerations, 11c would seem to have the greatest likelihood of diminished reactivity. However, 11b was the consistent outlier, with $11 \mathrm{a}$ and 11c remaining comparable throughout, providing the steric demands of 11c were met. Accordingly, we considered physical properties as the source of this anomaly. Empirical observations recorded during experimental set up suggested $11 \mathrm{~b}$ was less soluble in the reaction mixture than 11a or 11c. BMIDA substrates exhibit low solubility in many organic solvents - a property that enables their facile purification. ${ }^{[50]}$ While many BMIDA-based reactions are performed in solvents such as DMF presumably to aid solubility of these compounds, other solvents have been used, such as 1,4-dioxane, THF, and PhMe. ${ }^{[4 d, f, 5 n]}$

To gauge whether solubility may be a factor, we analyzed the solubility of $11 \mathrm{a}, \mathbf{1 1 b}$, and $11 \mathrm{c}$ in THF at room temperature, and obtained the following values: 11a, $56 \mathrm{mg} / \mathrm{mL}, 11 \mathrm{~b}, 19$ $\mathrm{mg} / \mathrm{mL}, 11 \mathrm{c}, 27 \mathrm{mg} / \mathrm{mL}$. 11b was found to be markedly less soluble than $11 \mathrm{a}$ and $11 \mathrm{c}$. We believe that this lower solubility may contribute to the observed discrepancy in reaction efficiency when using $\mathbf{1 1 b}$

2. Efficiency of Speciation Control with orthoSubstituted BMIDA. The cross-coupling of substituted haloaryl BMIDA (6c, 6d, 6g, Figure 2 and 6o-v Figure 4) were typically reasonably effective, providing yields of BPin products in the region of $50-70 \%$. However, we noticed a particular disparity when certain ortho-substituted BMIDA components were used. Specifically, when a methoxy or methyl ester substituent was located ortho to the BMIDA group, we observed little to no conversion to the desired BPin product (Figure 4, 6s-6v). In both cases the initial cross-coupling and hydrolysis to the boronic acid were sufficiently effective; however, the turnover of pinacol in order to form the desired BPin ester was found to be problematic. For $\mathrm{MeO}$-substituted products, $\mathbf{6 s}$ and $\mathbf{6 t}$, the reaction tended to produce only the biphenyl boronic acid intermediate $\mathbf{5 b}$ even after extended periods of time, suggesting a sluggish esterification process (Scheme 9a). The reasons for this are unclear; although we suspect this could be due to an intramolecular O-B Lewis pair interaction (as shown in $\mathbf{5 b}$ ). ${ }^{[25]}$ Such an interaction may inhibit the esterification process. However, NMR analysis did not confirm any deviation of the ${ }^{11} B$ signal for this species. Regioisomeric MeO-substitution did not present this issue (for example, $6 \mathbf{r}$, Figure 4).

Conversion to BPin was similarly poor for the ortho-ester substituted products $6 \mathbf{u}$ and $6 \mathbf{v}$. For these reactions, we observed a large quantity of the protodeboronated biphenyl product 19 (Scheme 9b). We believe this is due to the proximity of the electron-withdrawing ester functionality, which leads to accelerated rates of protodeboronation. ${ }^{[23 \mathrm{~b}]}$ It should also be noted that ortho-F was tolerated and did not provide any issues with either the esterification process or protodeboronation (see $6 \mathrm{c}, 6 \mathrm{~d}, 6 \mathrm{~g}$, Figure 2). (a) Inhibition of esterification with ortho-OMe

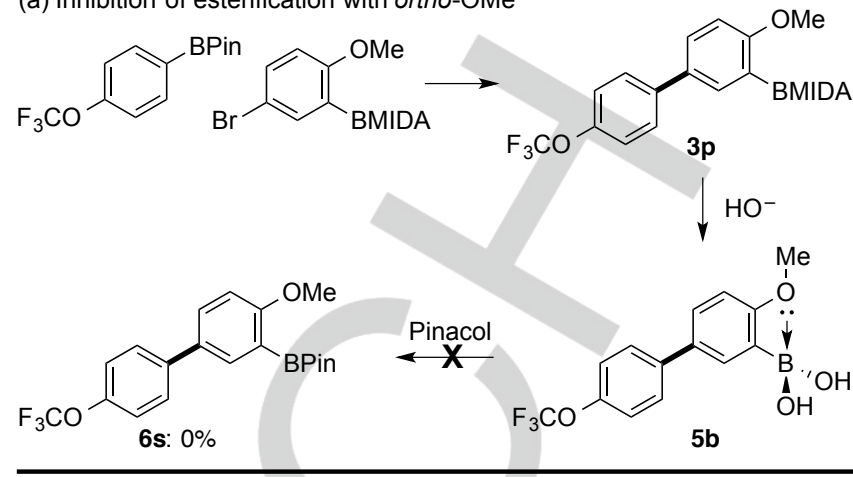

(b) Protodeboronation with ortho- $\mathrm{CO}_{2} \mathrm{Me}$<smiles>COC(=O)c1cc(-c2ccc(OC(C)(C)C)cc2)ccc1Br</smiles><smiles>COC(=O)c1cc(-c2ccc(OC(F)(F)F)cc2)ccc1Br</smiles><smiles>COC(=O)c1cc(-c2ccc(OC(F)(F)F)cc2)ccc1Br</smiles>
6s: $0 \%$

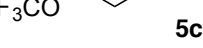

Scheme 9. Inhibition of esterification (a) and protodeboronation (b) when using ortho-substituted bromophenyl BMIDA reagents.

Manipulation of Boron Speciation Equilibria - Control Reactions. We believe the formal homologation reaction relies upon the simultaneous control of a series of boron speciation equilibria (Scheme 10). Cross-coupling of BPin 1 with conjunctive BMIDA 2 provides the expected adduct $3 .^{[4]]} \mathrm{A}$ frequently overlooked and generally discarded by-product of this process is the boric acid ester 4 . Both of these intermediate boron species, 3 and $\mathbf{4}$, can then participate in independent equilibria that can be modulated via $\mathrm{pH}$ control. ${ }^{[12,13]}$

Liberation of pinacol requires hydrolysis of 4 and control over 2:1 complex (20) formation. ${ }^{[12]}$ Hydrolysis of 4 under aqueous basic conditions delivers $\mathrm{B}(\mathrm{OH})_{3}$ (and the boronate derivative 21), both of which will be sequestered to the basic phase. ${ }^{[12,26]}$ Hydrolysis of $\mathbf{3}$ under basic conditions liberates the corresponding boronic acid $\mathbf{5},{ }^{[4 \mathrm{e}, 5 \mathrm{~d}, \mathrm{~g}, \mathrm{q}]}$ which can establish a series of equilibria including formation of the boronate $\mathbf{2 2}$ and boroxine 23. ${ }^{[27]}$ Esterification of boronic acids (5) and the corresponding boronate derivatives (22) with 1,2-diols is accelerated at high $\mathrm{pH}$, with the former being the kinetically more competent species. ${ }^{[13]}$ Following esterification, the newly 
generated BPin 6 will exist as the thermodynamically favored boronate $\mathbf{2 4}$, with $\mathbf{6}$ isolated upon completion of the reaction.
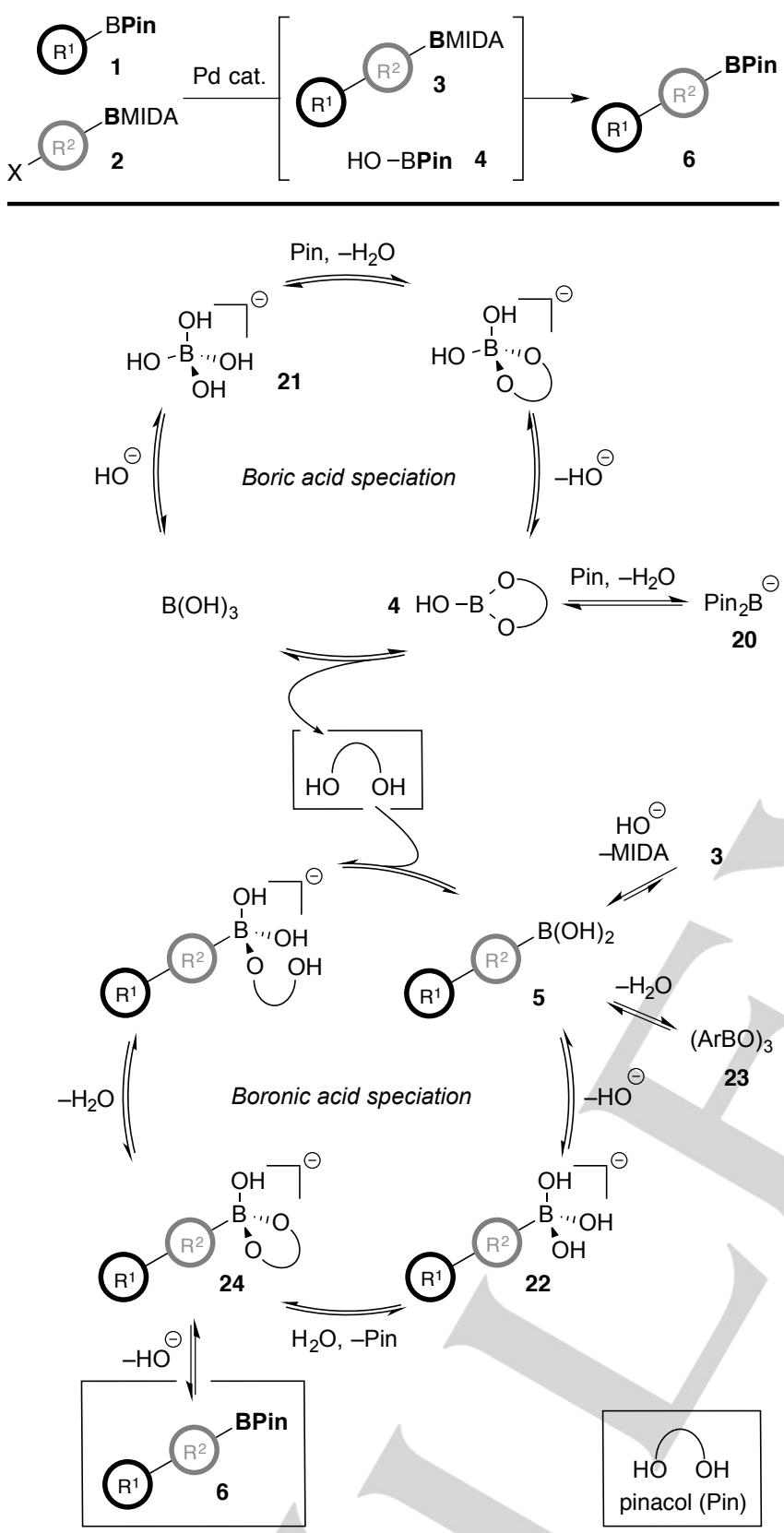

Scheme 10. Main solution speciation equilibria associated with the formal homologation process.

The staging of the reaction is crucial. The initial crosscoupling of $\mathbf{1}$ and 2 to produce 3 must be complete before hydrolysis of $\mathbf{3}$ takes place. If $\mathbf{3}$ hydrolyzes prematurely to boronic acid 5 before consumption of 2 , competing crosscoupling may take place. Similarly, cross-coupling of $\mathbf{1}$ and $\mathbf{2}$ must be complete before generation of product $\mathbf{6}$ in order to avoid competing cross-coupling with 2 (see Scheme 2). Analysis of these events using independent reactions demonstrated that, under the optimized reaction conditions, cross-coupling is rapid and is complete in $<1 \mathrm{~h}$ whereas hydrolysis of BMIDA intermediate 3 requires approximately $4 \mathrm{~h}$. Accordingly, oligomerization can be robustly avoided with this hydrolysis latency period. For the benchmark reaction, production of the desired BPin product $\mathbf{6 a}$ vs. presence/consumption of the intermediate BMIDA 3a could be followed by HPLC (Chart 3).

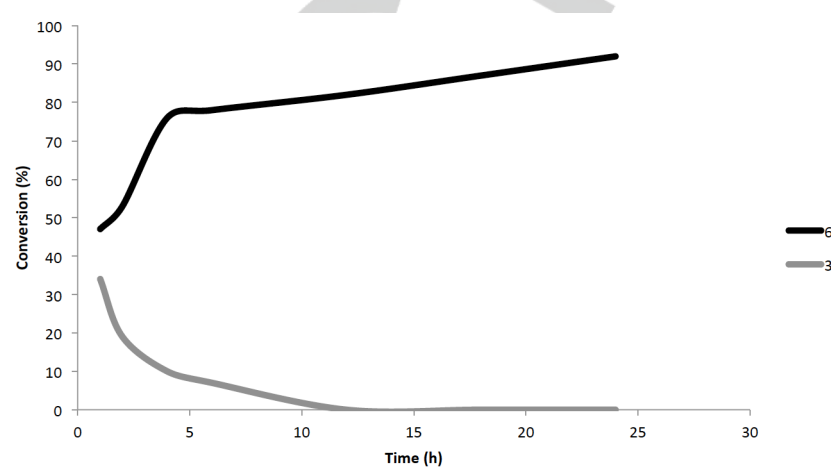

Chart 3. Production of $6 \mathbf{a}$ and presence/consumption of $3 \mathbf{a}$. Determined by HPLC analysis.

Throughout, no boronic acid 5a was detected, in agreement with previous observations that the esterification process is rapid and the efficiency of the reaction, under the optimized conditions, is directly linked to the efficiency of cross-coupling. Indeed, independent treatment of $\mathbf{5 a}$ with pinacol under the reaction conditions delivers quantitative formation of $6 \mathrm{a}$ in $<1 \mathrm{~h}$ (Scheme 11a). Similarly, $\mathbf{5 a}$ is quantitatively converted to $\mathbf{6 a}$ under representative reaction conditions from the byproduct from the initial Suzuki-Miyaura cross-coupling 4 (Scheme 11b).

(a) Formation of $\mathbf{6 a}$ from $\mathbf{5 a}$.

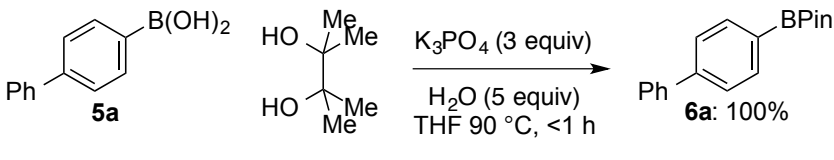

(b) Formation of $\mathbf{6 a}$ from $\mathbf{4}$ and $\mathbf{5 a}$.

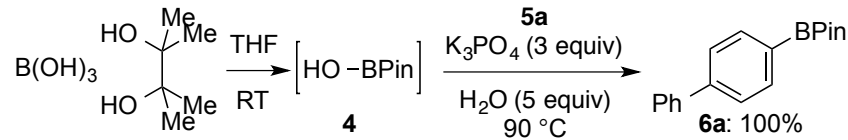

Scheme 11. Conversion of $5 \mathbf{a}$ to $\mathbf{6} \mathbf{a}$ under representative reaction conditions. Determined by HPLC analysis.

To ensure no other possible esterification pathways, we conducted a series of control experiments. Treatment of $\mathbf{3 a}$ with pinacol under the reaction conditions either in the presence or absence of base was informative (Scheme 12). 


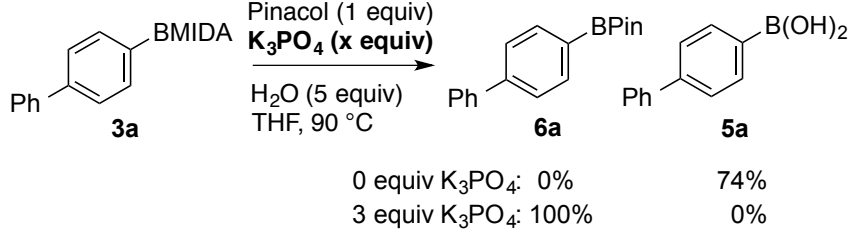

Scheme 12. Esterification of $3 a$ using pinacol to deliver $6 a$ in the presence and absence of base. Determined by HPLC analysis.

In the absence of base, $\mathbf{3 a}$ is converted to the boronic acid derivative $\mathbf{5 a}$ only. However, when base is included, $\mathbf{3 a}$ is converted smoothly to the BPin adduct $\mathbf{6 a}$. These results support a mechanism in which, when base is present, the hydrolysis of BMIDA $\mathbf{3} \mathbf{a}$ to boronic acid $\mathbf{5 a}$ is followed by subsequent esterification (Scheme 13, pathway A). In the absence of base, pinacol engages BMIDA to induce hydrolysis to the boronic acid $\mathbf{5 a}$. In doing so, a pinacol-MIDA ester (25 or 26) is generated, disabling boronic acid esterification (Scheme 13, pathway $\mathrm{B}$ ). boronate derivative $\mathbf{2 4}$, which is the thermodynamic end point for the boronic acid species in the reaction mixture. Direct hydrolysis of BPin, under basic conditions, is exceedingly difficult. Indeed, exposure of $\mathbf{6 a}$ to the reaction conditions, even for prolonged reaction times, failed to deliver any of the derivative biaryl boronic acid $\mathbf{5 a}$ (Scheme 14).<smiles>Brc1ccccc1</smiles>

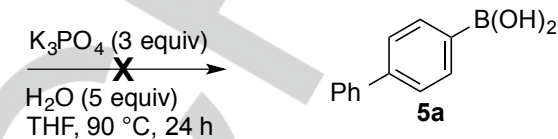

Scheme 14. Attempted hydrolysis of $6 \mathbf{a}$ to $5 \mathbf{a}$ under the reaction conditions.

Hydrolysis of BPin is more readily achieved by exploiting speciation equilibria with the addition of a second boron species, such as a polymeric phenyl boronic acid, relying upon equilibrium distortion to completely drive pinacol transfer. ${ }^{[22 a, b]}$ In this regard, treatment of PhBPin 10 with boronic acid $\mathbf{5 a}$ leads to equilibration to deliver mixtures of $\mathbf{5 a}$ and $\mathbf{6 a}$ (Scheme 15).
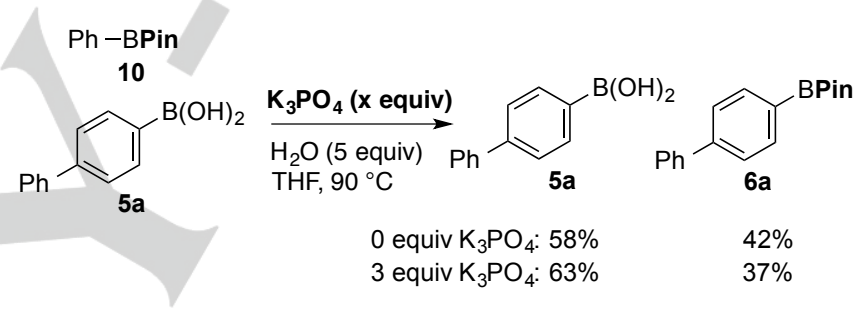

Scheme 15. Equilibration of 5a and 10. Determined by HPLC analysis.

This observation supports the proposed sequence of events, in particular a rapid Suzuki-Miyaura cross-coupling that is complete before hydrolysis of $\mathbf{3 a}$. If $\mathbf{3 a}$ were hydrolyzed before consumption of 10 , equilibration of $5 \mathbf{a}$ and $\mathbf{6 a}$ would lead to problems with oligomerization from residual 11a present in the reaction mixture due to the higher cross-coupling reactivity of the boronic acid $\mathbf{5 a}$ than the BPin starting material $\mathbf{1 0}$.

All of the above observations support the following sequence of events for the formal homologation reaction: (1) a rapid Suzuki-Miyaura cross-coupling; (2) a comparatively slow BMIDA hydrolysis; and (3) a rapid esterification of the liberated boronic acid. The reaction is also highly dependent upon (1) the nature of the base, which must possess good solubility and guarantee a suitable $\mathrm{pH}$ to enable speciation control and (2) the thermodynamic stability of the BPin product.

\section{Conclusions}

In summary, the fundamental physical properties of inorganic bases enable the formation of an in situ desiccant that controls the availability of aqueous base during Suzuki-Miyaura cross-coupling of haloaryl and haloalkenyl BMIDA esters. This internal aqueous base control mechanism enables the crosscoupling to be readily conducted with speciation control possible high efficiency of the reaction (Figure 2), the reverse process is unfavorable. The BPin product $\mathbf{6 a}$ is rapidly converted to the 
by temperature modulation to enable the production of BPin adducts or BMIDA adducts. The requirements for effective speciation control have been investigated and the sequence of events supported by a series of independent transformations.

\section{Acknowledgements}

This work was supported by the Engineering and Physical Sciences Research Council (EPSRC). We thank the EPSRC UK National Mass Spectrometry Facility at Swansea University for analyses and GlaxoSmithKline for financial support.

\section{Keywords: boron • chemoselectivity $\bullet$ cross-coupling •} palladium $\cdot$ speciation

$\dagger \quad$ Throughout, $\mathrm{pK}_{\mathrm{a}}$ refers to the $\mathrm{pK}_{\mathrm{a}}$ of the conjugate acid.

[1] For reviews of the Suzuki-Miyaura reactions, see: a) N. Miyaura, A Suzuki, Chem. Rev. 1995, 95, 2457-2483; b) C. Valente, M. C. Organ, The Contemporary Suzuki-Miyaura Reaction In Boronic Acids: Preparation and Applications in Organic Synthesis and Medicine (Ed.: D. G. Hall), Wiley-VCH, Weinheim, 2005, vol. 2, pp 213-262; c) Science of Synthesis Cross Coupling and Heck-Type Reactions; G. A. Molander, J. P. Wolfe, M. Larhed, Eds.; Thieme: New York, 2012; d) A. J. J. Lennox, G. C. Lloyd-Jones, Angew. Chem. Int. Ed. 2013, 52, 7362-7370; Angew. Chem. 2013, 125, 7506-7515; e) A. J. J. Lennox, G. C. Lloyd-Jones, Chem. Soc. Rev. 2014, 43, 412-443.

[2] For reviews of iterative cross-coupling using MIDA- and DAN-derived boronic esters, see: a) E. P. Gillis, M. D. Burke, Aldrichimica Acta 2009, 42, 17-27; b) C. Wang, F. Glorius, Angew. Chem. Int. Ed. 2009, 48, 5240-5244; Angew. Chem. 2009, 121, 5342-5346; c) M. Tobisu, N. Chatani, Angew. Chem. Int. Ed. 2009, 48, 3565-3568; Angew. Chem. 2009, 121, 3617-3620; d) J. W. B. Fyfe, A. J. B. Watson, Synlett DOI: ST-2015-P0028-SP.

[3] First development of BMIDA: a) R. Contreras, C. Garcia, T. Mancilla, B. Wrackmeyer, J. Organomet. Chem. 1983, 246, 213-217; b) B. Garrogues, M. Mulliez, A. Raharinirina, J. Organomet. Chem. 1986, 302, 153-158; c) T. Mancilla, R. Contreras, B. Wrackmeyer, J. Organomet. Chem. 1986, 307, 1-6; d) B. Garrogues, M. Mulliez, J. Organomet. Chem. 1986, 314, 19-24.

[4] Use of BMIDA in iterative cross-coupling: E. M. Woerly, J. Roy, M. D. Burke, Nature Chem. 2014, 6, 484-491; b) S. Fujii, S. Y. Chang, M. D. Burke, Angew. Chem. Int. Ed. 2011, 50, 7862-7864; c) S. J. Lee, T. M. Anderson, M. D. Burke, Angew. Chem. Int. Ed. 2010, 49, 8860-8863; d) E. M. Woerly, A. H. Cherney, E. K. Davis, M. D. Burke, J. Am. Chem. Soc. 2010, 132, 6941-6943; e) S. J. Lee, K. C. Gray, J. S. Paek, M. D. Burke, J. Am. Chem. Soc. 2008, 130, 466-468; f) E. P. Gillis, M. D. Burke, J. Am. Chem. Soc. 2007,129, 6716-6717.

[5] For other uses/preparations of BMIDA reagents, see: a) S. Adachi, A. B. Cognetta 3rd, M. J. Niphakis, Z. He, A. Zajdlik, J. D. St. Denis, C. C. G. Scully, B. F. Cravatt, A. K. Yudin, Chem. Commun. 2015, 51, 36083611; b) J. Cornil, P.-G. Echeverria, P. Phansavath, V. Ratovelomanana-Vidal, A. Guérinot, J. Cossy, Org. Lett. 2015, 17, 948-951; c) J. D. St. Denis, A. Zajdlik, J. Tan, P. Trinchera, C. F. Lee, Z. He, S. Adachi, A. K. Yudin, J. Am. Chem. Soc. 2014, 136, 1766917673; d) J. D. St. Denis, C. C. G. Scully, C. F. Lee, A. K. Yudin, Org. Lett. 2014, 16, 1338-1341; e) L. Xu, P. Li, Synlett 2014, 25, 17991802; f) L. Xu, S. Ding, P. Li, Angew. Chem. Int. Ed. 2014, 53, 18221826; Angew. Chem. 2014, 126, 1853-1857; g) N. A. Isley, F. Gallou, B. H. Lipshutz, J. Am. Chem. Soc. 2013, 135, 17707-17710; h) E. M. Woerly, J. E. Miller, M. D. Burke, Tetrahedron 2013, 69, 7732-7740; i)
Z. He, P. Trinchera, S. Adachi, J. D. St. Denis, A. K. Yudin, Angew. Chem. Int. Ed. 2012, 51, 11092-11096; Angew. Chem. 2012, 124, 11254-11258; j) G. R. Dick, E. M. Woerly, M. D. Burke, Angew. Chem. Int. Ed. 2012, 51, 2667-2672; k) H. Wang, C. Grohmann, C. Nimphius, F. Glorius, J. Am. Chem. Soc. 2012, 134, 19592-19595; I) J. Li, M. D. Burke, J. Am. Chem. Soc. 2011,133, 13774-13777; m) E. M. Woerly, J. R. Struble, N. Palyam, S. P. O'Hara, M. D. Burke, Tetrahedron 2011, 67, 4333-4343; n) G. R. Dick, D. M. Knapp, E. P. Gillis, M. D. Burke, Org. Lett. 2010, 12, 2314-2317; o) J. R. Struble, S. J. Lee, M. D. Burke, Tetrahedron 2010, 66, 4710-4718; p) S. G. Ballmer, E. P. Gillis, M. D. Burke, Org. Syn. 2009, 86, 344-359; q) D. M. Knapp, E. P. Gillis, M. D. Burke, J. Am. Chem. Soc. 2009, 131, 6961-6963; r) B. E. Uno, E. P. Gillis, M. D. Burke, Tetrahedron 2009, 65, 3130-3138; s) E. P. Gillis, M. D. Burke, J. Am. Chem. Soc. 2008, 130, 14084-14085.

[6] Use of DAN in iterative cross-coupling: a) H. Noguchi, K. Hoj, M. Suginome, J. Am. Chem. Soc. 2007, 129, 758-759; b) H. Noguchi, T. Shioda, C.-M. Chou, M. Suginome, Org. Lett. 2008, 10, 377-380; c) N. Iwadate, M. Suginome, Org. Lett. 2009, 11, 1899-1902; d) N. Iwadate, M. Suginome, Chem. Lett. 2010, 39, 558-560; e) N. Iwadate, M. Suginome, J. Am. Chem. Soc. 2010, 132, 2548-2549.

[7] For other uses/preparations of DAN reagents, see: a) H. Yoshida, Y. Takemoto, K. Takaki, Chem. Commun. 2015, DOI: 10.1039/c5cc00439j; b) X. Feng, H. Jeon, J. Yun, Angew. Chem. Int. Ed. 2013, 52, 3989-3992; Angew. Chem. 2013, 125, 4081-4084; c) H. Ihara, M. Koyanagi, M. Suginome, Org. Lett. 2011, 13, 2662-2665; d) J. C. H. Lee, R. McDonald, D. G. Hall, Nature Chem. 2011, 3, 894-899.

[8] For selected examples of the preparation and chemoselective manipulation of multiboron species, see: a) S. N. Mlynarski, C. H. Schuster, J. P. Morken, Nature 2014, 505, 386-390; b) C. Sun, B. Potter, J. P. Morken, J. Am. Chem. Soc. 2014, 136, 6534-6537; c) J. Jiao, K. Hyodo, H. Hu, K. Nakajima, Y. Nishihara, J. Org. Chem. 2014, 79, 285-295; d) K. Endo, T. Ohkubo, M. Hirokami, T. Shibata, J. Am. Chem. Soc. 2010, 132, 11033-11035. See also refs 5e, 5f, 7b, 7d.

[9] J. W. B. Fyfe, C. P. Seath, A. J. B. Watson, Angew. Chem. Int. Ed. 2014, 53, 12077-12080; Angew. Chem. 2014, 126, 12273-12276. See also: J. J. Molloy, R. P. Law, J. W. B. Fyfe, C. P. Seath, D. J. Hirst, A. J. B. Watson, Org. Biomol. Chem. 2015, 13, 3093-3102.

[10] For general information see: Boronic Acids: Preparation and Applications in Organic Synthesis and Medicine (Ed.: D. G. Hall), WileyVCH, Weinheim, 2005.

[11] H. C. Brown, Organic Synthesis via Organoboranes, Wiley Interscience, New York, 1975.

[12] J. P. Lorand, J. O. Edwards, J. Org. Chem. 1959, 24, 769-774.

[13] For informative studies on the esterification of boronic acids, see: a) $\mathrm{Y}$. Furikado, T. Nagahata, T. Okamoto, T. Sugaya, S. Iwatsuki, M. Inamo, H. D. Takagi, A. Odani, K. Ishihara, Chem. Eur. J. 2014, 20, 1319313202; b) T. Okamoto, A. Tanaka, E. Watanabe, T. Miyazaki, T. Sugaya, S. Iwatsuki, M. Inamo, H. D. Takagi, A. Odani, K. Ishihara, Eur. J. Inorg. Chem. 2014, 2389-2395; c) E. Watanabe, C. Miyamoto, A. Tanaka, K. lizuka, S. Iwatsuki, M. Inamo, H. D. Takagi, K. Ishihara, Dalton Trans. 2013, 42, 8446-8453; d) M. A. Martinez-Aguirre, R. Villamil-Ramos, J. A. Guerrero-Alvarez, A. K. Yatsmirsky, J. Org. Chem. 2013, 78, 4674-4684; e) C. Miyamoto, K. Suzuki, S. Iwatsuki, M. Inamo, H. D. Takagi, K. Ishihara, Inorg. Chem. 2008, 47, 1417-1419; f) S. Iwatsuki, S. Nakajima, M. Inamo, H. D. Takagi, K. Ishihara, Inorg. Chem. 2007, 46, 354-356; g) J. Yan, G. Springsteen, S. Deeter, B. Wang, Tetrahedron 2004, 60, 11205-11209; h) L. I. Bosch, T. M. Fyles, T. D. James, Tetrahedron 2004, 60, 11175-11190; i) G. Springsteen, B. Wang, Tetrahedron 2002, 58, 5291-5300; j) R. Pizer, C. A. Tihal, Polyhedron 1996, 15, 3411-3416; k) L. Babcock, R. Pizer, Inorg. Chem. 1980, 19, 56-61.

[14] CRC Handbook of Chemistry and Physics, $94^{\text {th }}$ Edition (Ed.: W. M. Haynes), Taylor and Francis, Boca Raton, Florida, 2014 
[15] For the use of bromothiophenyl BMIDA reagents as a method for the preparation of polymeric thiophenes, see: J. A. Carrillo, M. J. Ingleson, M. L. Turner, Macromolecules 2015, 48, 979-986.

[16] C. Amatore, A. Jutand, G. Le Duc, Chem. Eur. J. 2011, 17, 2492-2503.

[17] C. Amatore, A. Jutand, G. Le Duc, Chem. Eur. J. 2012, 18, 6616-6625.

[18] M. B. Smith, March's Advanced Organic Chemistry: Reactions, Mechanism, and Structure, $7^{\text {th }}$ Edition, Wiley, Hoboken, New Jersey, 2013. See also ref 14

[19] For example, see: a) H. Deng, P. Peljo, T. J. Stockmann, L. Qiao, T. Vainikka, K. Kontturi, M Opallo, H. H. Girault, Chem. Commun. 2014 50, 5554-5557; b) W. Murakami, K. Eda, M. Yamamoto, T. Osakai, J. Electroanal. Chem. 2013, 704, 38-43; c) D. Rose, I. Benjamin, J. Phys Chem. B 2009, 113, 9296-9303; d) P. Sun, F. O. Laforge, M. V. Mirkin, J. Am. Chem. Soc. 2007, 129, 12410-12411.

[20] L. Greenspan, J. Res. Nat. Bur. Stand. 1977, 81A, 89-96.

[21] For selected reviews of biaryl phosphane ligands, see: a) D. S. Surry, S L. Buchwald, Angew. Chem. Int. Ed. 2008, 47, 6338-6361; Angew. Chem. 2008, 120, 6438-6461; b) R. Martin, S. L. Buchwald, Acc. Chem. Res. 2008, 41, 1461-1473.

[22] a) T. E. Pennington, C. Kardiman, C. A. Hutton Tetrahedron Lett. 2004 45, 6657-6660; b) S. J. Coutts, J. Adams, D. Krolikowski, R. J. Snow,
Tetrahedron Lett. 1994, 35, 5109-5112; c) D. S. Matteson, R. Ray, R. R. Rocks, D. J. S. Tsai, Organometallics 1983, 2, 1536-1543.

[23] For selected studies of protodeboronation, see: a) G. Noonan, A. G. Leach, Org. Biomol. Chem. 2015, 13, 2555-2560; b) J. Lozada, Z. Liu, D. M. Perrin, J. Org. Chem. 2014, 79, 5365-5368; c) H. G. Kuivila, J. F. Reuwer Jr., J. A. Mangravite, Can. J. Chem. 1963, 41, 3081-3090; d) H. G. Kuivila, K. V. Nahabedian, J. Am. Chem. Soc. 1961, 83, 2167-2174; e) H. G. Kuivila, K. V. Nahabedian, J. Am. Chem. Soc. 1961, 83, 21642166; f) H. G. Kuivila, K. V. Nahabedian, J. Am. Chem. Soc. 1961, 83, 2159-2163.

[24] I. J. S. Fairlamb, Chem. Soc. Rev. 2007, 36, 1036-1045

[25] For an example of a four-membered cyclic Lewis pair, see: P. Spies, G. Erker, G. Kehr, K. Bergander, R. Fröhlich, S. Grimme, D. W. Stephan, Chem. Commun. 2007, 5072-5074. For a recent review of frustrated Lewis pairs, see: D. W. Stephan, Acc. Chem. Res. 2015, 48, 306-316.

[26] For discussion of the basic biphase, see: A. J. J. Lennox, G. C. LloydJones, J. Am. Chem. Soc. 2012, 134, 7431-7441. See also refs 1d, 1e.

[27] Other binary and ternary boronate species, such as those derived from the inorganic base are not shown. For examples, see ref $13 \mathrm{~h}$. See also: M. Sanjoh, D. lizuka, A. Matsumoto, Y. Miyahara, Org. Lett. 2015, 17, 588-591. 


\section{Entry for the Table of Contents}

\section{FULL PAPER}

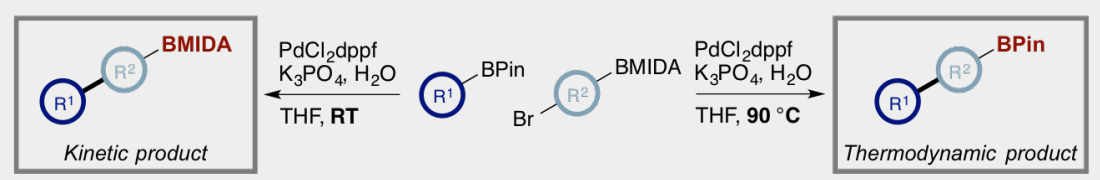

Boronic acid solution speciation can be controlled during the Suzuki-Miyaura crosscoupling of haloaryl MIDA boronic esters to enable chemoselective access to either BMIDA or BPin products. The reaction is contingent upon control of the basic biphase and product distribution can be controlled by temperature regulation. Control experiments and analysis of the physical properties of inorganic bases have provided insight into the mechanistic operation of the formal homologation process.
James W. B. Fyfe, Elena Valverde, Ciaran P. Seath, Alan R. Kennedy, Joanna M. Redmond, Niall A. Anderson, and Allan J. B. Watson*

Page No. - Page No.

Speciation control during SuzukiMiyaura cross-coupling of haloaryl and haloalkenyl MIDA boronic esters 